\title{
Restructuring of Supported PtSn Bimetallic Catalysts during Aqueous Phase Oxidation of 1,6-Hexanediol
}

\author{
Jiahan Xie, Derek D. Falcone, Robert J. Davis * \\ Department of Chemical Engineering, University of Virginia, 102 Engineers' Way, PO \\ Box 400741, Charlottesville, VA 22904-4741, United States
}

University of Virginia, Department of Chemical Engineering,

102 Engineers' Way, PO Box 400741, Charlottesville, VA 22904-4741, United States

${ }^{*}$ Author to whom correspondence is addressed

Phone: 1 - 434 - 924 - 6284

Email: rjd4f@virginia.edu 


\section{Abstract:}

A series of carbon-supported bimetallic PtSn catalysts having various $\mathrm{Pt} / \mathrm{Sn}$ molar ratios was prepared and tested in the oxidation of 1,6-hexanediol with $1 \mathrm{MPa}$ dioxygen at $343 \mathrm{~K}$ in aqueous solvent. The $\mathrm{PtSn} / \mathrm{C}$ catalysts, which were initially reduced with sodium borohydride, did not produce Pt-Sn alloy particles. Instead, the catalysts were composed of $\mathrm{SnO}_{\mathrm{x}}$ moieties that were well-dispersed on the surfaces of the carbon support and the Pt nanoparticles. Subsequent treatment in $\mathrm{H}_{2}$ at $673 \mathrm{~K}$ induced Pt-Sn alloy formation. Whereas addition of $\mathrm{SnO}_{\mathrm{x}}$ to the $\mathrm{Pt}$ nanoparticles promoted the initial 1,6-hexanediol oxidation rate by $39 \%$, the formation of Pt-Sn alloy particles decreased the initial rate. Under 1,6-hexanediol oxidation conditions, however, the Pt-Sn alloy phase separated, leading to the recovery of the catalytic activity. No significant change of product distribution was observed on bimetallic PtSn catalysts, regardless of the composition and structure.

\section{Key Words:}

$\mathrm{Pt}$; Sn; Heterogeneous bimetallic catalysts; Alcohol oxidation; Pt-Sn alloy; $\mathrm{Pt}-\mathrm{SnO}_{\mathrm{x}}$ interface; Catalyst restructuring. 


\section{Introduction:}

Bimetallic catalysts consisting of $\mathrm{Pt}$ and $\mathrm{Sn}$ have been studied extensively in hydrogenation ${ }^{1-6}$, hydrocarbon reforming ${ }^{7-11}$, CO oxidation ${ }^{12,13}$ and alcohol electro-oxidation ${ }^{14-32}$ because they have demonstrated enhanced activity, selectivity and/or stability, compared to monometallic Pt catalysts. The addition of $\mathrm{Sn}$ to $\mathrm{Pt}$ presumably leads to the formation of unique active sites, specifically those associated with Pt-Sn alloys and $\mathrm{Pt}-\mathrm{SnO}_{\mathrm{x}}$ interfaces. When $\mathrm{Pt}$ and $\mathrm{Sn}$ are in close proximity, an electronic interaction between the components and modification of Pt ensembles can alter the catalytic performance. A large body of work has reported on the promotional effects of Sn, which are attributed mainly to a change in the adsorption energy of certain molecules ${ }^{6,12,14,20,25,27,28,33,34}$, a modified rate of $\mathrm{C}-\mathrm{C}$ bond cleavage reactions ${ }^{1,20,27,30}$, the efficient removal of strongly adsorbed poisons ${ }^{17,25,30}$ and the introduction of acid sites ${ }^{8,10,11}$ and/or $\mathrm{O}_{2}$ adsorption site ${ }^{12}$. For example, in the hydrogenation of $\alpha, \beta$-unsaturated aldehyde, the dilution of the $\mathrm{Pt}$ ensembles by $\mathrm{SnO}_{\mathrm{x}}$ hindered the adsorption of $\mathrm{C}=\mathrm{C}$ groups relative to $\mathrm{C}=\mathrm{O}$ groups, thus favoring preferential hydrogenation of the aldehyde to produce an unsaturated alcohol with high selectivity ${ }^{2-6}$. The added $\mathrm{SnO}_{\mathrm{x}}$ can also act as a Lewis acid site in hydrocarbon reforming reactions, which leads to a significant increase in activity ${ }^{8,11}$. In the oxidation of $\mathrm{CO}$, Michalak et al. attributed the promoted activity over a PtSn bimetallic catalyst to the $\mathrm{Pt}-\mathrm{SnO}_{\mathrm{x}}$ interface ${ }^{12}$. The $\mathrm{SnO}_{\mathrm{x}}$ provides an active site for $\mathrm{O}_{2}$ adsorption while $\mathrm{Pt}$ is covered with strongly adsorbed CO. 
In the electro-oxidation of alcohols, supported bimetallic PtSn electro-catalysts exhibited higher activity and stability compared to monometallic Pt electro-catalysts $15,19,26,32$. Although the addition of Sn often increases the activity of Pt by a factor of $2-$ $10^{18,19,21,24,27}$, Biallozor et al. reported a steady-state current density with a poly(3,4-dioxyethylenethiophene)-supported $\mathrm{PtSn}$ catalyst that was 2 orders of magnitude greater than that of Pt during the electro-oxidation of methanol ${ }^{15}$. Ishikawa et al. studied the oxidation of methanol on Pt-Sn alloy using density-functional theory (DFT) and suggested that the adsorption of both methanol and CO was weaker on the Pt-Sn alloy surface ${ }^{14}$, which may account for the faster rate and greater stability of the alloy. A lower adsorption energy of methanol and ethanol on the surface of Pt-Sn alloy was also observed in a temperature-programmed desorption (TPD) study ${ }^{35}$, which is consistent with DFT results. In addition to Pt-Sn alloy formation, the presence of $\mathrm{SnO}_{\mathrm{x}}$ adjacent to $\mathrm{Pt}$ ensembles is also thought to play an important role in the electro-oxidation of alcohols. Castro Luna et al. report that catalysts containing the largest amount of $\mathrm{SnO}_{\mathrm{x}}$ exhibited the best performance in ethanol oxidation ${ }^{31}$. The superior activity of a $\mathrm{SnO}_{\mathrm{x}}$-promoted catalyst was attributed to an enhancement in the dissociative adsorption of alcohol in the low potential region ${ }^{20,25}$. Furthermore, Pergato et al. and Rato et al. proposed that $\mathrm{SnO}_{\mathrm{x}}$ might promote the removal of adsorbed $\mathrm{CO}$ and other strongly-adsorbed remnants from C-C bond cleavage reaction ${ }^{28,29}$.

One potential complication with bimetallic catalysts is that their structure may change during the reaction. Whereas many studies correlate the catalytic performance of 
bimetallic particles to the structure of the as-prepared catalysts, changes in the structure of PtSn catalysts have been reported under both hydrogenation and oxidation conditions 12,15,25,36. To understand the promotional effect of $\mathrm{Sn}$ on Pt catalysts, it is therefore important to examine the influence of the reaction environment on catalyst structure.

The present work explores the influence of added Sn on Pt catalysts for the selective oxidation of 1,6-hexanediol (HDO). Oxidation of HDO can produce adipic acid (DA), which is one of the top ten commodity chemicals by volume ${ }^{37}$ and is widely used in the synthesis of nylon-6,6, for carpet fibers, tire reinforcements, upholstery and apparel ${ }^{38}$. Adipic acid is currently produced from a mixture of cyclohexanol and cyclohexanone via nitric acid oxidation, which emits a considerable amount of nitrous oxide $^{39,40}$. One promising environmentally-friendly route to produce adipic acid begins with hexose (glucose and fructose), derived from biomass. A high yield of 5-hydroxymethylfurfural (HMF) can be obtained from the dehydration of hexose, which can then be efficiently converted to HDO ${ }^{41,42}$ and subsequently oxidized to adipic acid. Among supported metal catalysts, Au has demonstrated the highest activity for polyol oxidation under basic conditions ${ }^{43}$. The use of base, however, is not attractive because of the cost involved in neutralizing the product stream to recover the free acid. Oxidation of alcohol over Pt does not require high concentration of base for the diacid production ${ }^{44,45}$. Unfortunately, severe deactivation can be observed during the oxidation of HDO over Pt catalysts, which was tentatively attributed to strongly adsorbed species generated from $\mathrm{C}-\mathrm{C}$ bond cleavage ${ }^{46}$. Since the addition of $\mathrm{Sn}$ to Pt may enhance the 
removal of strongly adsorbed species on the surface, PtSn bimetallic catalysts are promising candidates for the selective oxidation of HDO.

In this study, a series of carbon-supported PtSn bimetallic catalysts was prepared and evaluated in the oxidation of $\mathrm{HDO}$ in liquid water by $\mathrm{O}_{2}$ without the addition of base. Extensive characterization of the catalysts before and after reaction was performed to enable correlation of performance to catalyst structure and composition.

\section{Materials and Methods}

\subsection{Catalyst preparation}

All carbon-supported Pt and PtSn bimetallic catalysts were synthesized using a $\mathrm{NaBH}_{4}$ reduction method. The loading of Pt was always $3 \mathrm{wt} \%$ while the amount of $\mathrm{Sn}$ was varied. The Pt and $\mathrm{Sn}$ precursors used were $\mathrm{H}_{2} \mathrm{PtCl}_{4}$ and $\mathrm{Na}_{2} \mathrm{SnO}_{3}$ (Sigma-Aldrich), respectively, and activated carbon (Norit, Ultra SX) was used as the support. Activated carbon $(2 \mathrm{~g})$ was dispersed ultrasonically in $150 \mathrm{~cm}^{3}$ of a $1 \mathrm{mM} \mathrm{NaOH}$ solution (Aldrich) for $1 \mathrm{~h}$. The desired amount of $\mathrm{Na}_{2} \mathrm{SnO}_{3}$ and $0.3 \mathrm{mmol}$ of the $\mathrm{H}_{2} \mathrm{PtCl}_{4}$ were dissolved separately in $25 \mathrm{~cm}^{3}$ of $1 \mathrm{mM} \mathrm{NaOH}$ and added to the carbon slurry with vigorous stirring. The Pt and Sn precursors were reduced by the rapid addition of $10 \mathrm{~cm}^{3}$ of a freshly prepared $0.3 \mathrm{M} \mathrm{NaBH}_{4}$ solution (Aldrich). The slurry was left under vigorous stirring for 2 h. Finally, the slurry was filtered, washed thoroughly with distilled, deionized water and dried in air at room temperature. These catalysts are denoted as $x \mathrm{PtySn} / \mathrm{C}$, where $x: y$ is the nominal molar ratio of $\mathrm{Pt}$ to $\mathrm{Sn}$. 
The $x \mathrm{PtySn} / \mathrm{C}$ catalysts were then heated to $673 \mathrm{~K}$ at $1 \mathrm{~K} \mathrm{~min}^{-1}$ under $100 \mathrm{~cm}^{3} \mathrm{~min}^{-1}$ of flowing dihydrogen (GT\&S 99.999\%) and reduced for $2 \mathrm{~h}$. These catalysts are denoted as $x \mathrm{PtySn} / \mathrm{C}-\mathrm{H}$. To study the potential structural and compositional changes of $x \mathrm{Pty} \mathrm{Sn} / \mathrm{C}-\mathrm{H}$, catalysts were recovered after HDO oxidation, washed with distilled and deionized water and dried at room temperature. The used catalyst after reaction was denoted as $x \mathrm{Pty} \mathrm{Sn} / \mathrm{C}-\mathrm{H}-\mathrm{R}$. In addition, the $3 \mathrm{Pt} 3 \mathrm{Sn} / \mathrm{C}$ catalyst was also heated to $473 \mathrm{~K}$ at $1 \mathrm{~K} \mathrm{~min}^{-1}$ under $100 \mathrm{~cm}^{3} \min ^{-1}$ of flowing dihydrogen and treated for $4 \mathrm{~h}$, giving a sample denoted as 3Pt3Sn/C-473H.

\subsection{Catalyst characterization}

The fraction of available $\mathrm{Pt}$ on the surface of a catalyst was estimated by $\mathrm{H}_{2}$ chemisorption using a Micromeritics ASAP 2020 automated adsorption analyzer. The catalysts were heated to $473 \mathrm{~K}$ at $4 \mathrm{~K} \mathrm{~min}^{-1}$ under flowing $\mathrm{H}_{2}$ (GT\&S 99.999\%) and reduced for $2 \mathrm{~h}$. The samples were then evacuated for $2 \mathrm{~h}$ at $473 \mathrm{~K}$ before being cooled to $308 \mathrm{~K}$ for analysis in the pressure range of $1.33-59.9 \mathrm{KPa}$. The amount of exposed Pt was evaluated by the total amount of $\mathrm{H}_{2}$ adsorbed, extrapolated to zero pressure, assuming a stoichiometry $\left(\mathrm{H} / \mathrm{Pt}_{\text {surf }}\right)$ equal to unity.

The X-ray diffraction (XRD) patterns were recorded using a PANalytical X'Pert Pro MPD (Multi-Purpose Diffractometer) instrument with $\mathrm{Cu} \mathrm{K \alpha}$ radiation (45 kV, $40 \mathrm{~mA}$ ) and scanning of $2 \theta$ from $20^{\circ}$ to $80^{\circ}$ with a step size of $0.0025^{\circ}$ at a rate of $0.125^{\circ} \min ^{-1}$. 
Transmission electron microscopy (TEM) was performed on a JEOL 2000 operating at $200 \mathrm{kV}$ to obtain the metal particle size distribution of the catalysts. The high-resolution transmission electron microscopy (HR-TEM) and scanning transmission electron microscopy (STEM) were performed on an FEI Titan 80-300 operating at 300 $\mathrm{kV}$ that is equipped with a Gatan 794 Multi-scan Camera (EFTEM) and an energy dispersive spectrometer for elemental X-ray analysis. To prepare a sample, $\sim 1 \mathrm{mg}$ of catalyst was suspended in $10 \mathrm{~cm}^{3}$ of ethanol by agitating the mixture for $30 \mathrm{~min}$ in a sonication bath. A copper grid with a holey carbon film was dipped into the solution to capture the particles and the ethanol was thoroughly evaporated before microscopy.

The X-ray photoelectron spectroscopy (XPS) was carried out at the Nanomaterials Core Characterization Facility of the Virginia Commonwealth University (Richmond, VA), utilizing a Thermo Scientific ESCALAB 250 spectrometer equipped with a focused monochromatic Al K $\alpha$ X-ray radiation source $(1486.6 \mathrm{eV})$ and a hemispherical analyzer with a 6-element multichannel detector. The incident X-ray beam was $45^{\circ}$ off normal to the sample while the X-ray photoelectron detector was normal to the sample. A large area magnetic lens with a $500 \mu \mathrm{m}$ spot size in constant analyzer energy mode was utilized with a pass energy of $20 \mathrm{eV}$ for region scans. Charge compensation was employed during data collection with an internal electron flood gun $(2 \mathrm{eV})$ and a low energy external Arion flood gun. All spectra were deconvoluted with a curve fitting routine in CasaXPS software. The background was corrected using the linear method and the binding energy of the $\mathrm{C} 1 \mathrm{~s}$ peak assigned at $284.5 \mathrm{eV}$, which is attributed to the 
support, was used to reference the peak positions ${ }^{19}$. The integral of each peak was calculated after subtracting the background and fitting with a combination of Lorentzian asymmetric curves of variable proportion. The $\mathrm{Pt}: \mathrm{Sn}$ surface atomic ratios were calculated from peak areas normalized by atomic subshell photoionization cross sections of the corresponding element ${ }^{47}$. The detailed XPS curve fitting parameters are listed in Table S1.

Elemental analysis was used to determine some of the Pt and Sn weight loadings on the supported PtSn bimetallic catalysts and the concentration of leached $\mathrm{Pt}$ and $\mathrm{Sn}$ in the reaction solution after $4 \mathrm{~h}$ of HDO oxidation. Elemental analysis was performed by Galbraith Laboratories (2323 Sycamore Drive, Knoxville, TN 37921) using inductively coupled plasma - atomic emission spectroscopy (ICP-AES).

\subsection{1,6-Hexanediol (HDO) oxidation reactions}

Semi-batch alcohol oxidation reactions were performed in a $50 \mathrm{~cm}^{3}$ Parr Instrument Company 4592 batch reactor with a $30 \mathrm{~cm}^{3}$ glass liner. An aqueous $1 \mathrm{mM}$ HDO solution and $0.0132 \mathrm{~g}$ catalyst were added to the glass liner. The glass liner was inserted into the reactor, sealed, purged with He (GT\&S, 99.999\%), heated to $343 \mathrm{~K}$ and held for $20 \mathrm{~min}$. The reaction was initiated by pressurizing the reactor with $1 \mathrm{MPa}$ of $\mathrm{O}_{2}(\mathrm{GT} \& \mathrm{~S}, 99.993 \%)$. Liquid samples were periodically removed and the catalyst was filtered using a $0.2 \mu \mathrm{m}$ PTFE filter before product analysis with a Waters e2695 high performance liquid chromatograph (HPLC). The HPLC was equipped with refractive 
index detector. Product separation in the HPLC was accomplished on an Aminex HPX-87H column (Bio-Rad) operating at $318 \mathrm{~K}$ with an aqueous $5 \mathrm{mM} \mathrm{H}_{2} \mathrm{SO}_{4}$ solution as mobile phase flowing at $5 \mathrm{~cm}^{3} \mathrm{~min}^{-1}$. The retention times and calibration curves were determined by injecting known concentrations of standards. Carbon balances were always greater than $90 \%$.

The maximum $\mathrm{O}_{2}$ transport rate from the gas phase to the aqueous phase in the pressurized reaction system was determined by the sulfite oxidation method ${ }^{48}$. The amount of catalyst added to the reactor was chosen so that the alcohol oxidation rate would not be limited by $\mathrm{O}_{2}$ mass transfer from the gas to the liquid. Selectivity to a specific product is defined as moles of that product formed divided by moles of all products produced. The initial turnover frequency (TOF) [mol alcohol converted (mol metal $\left._{\text {surface }}\right)^{-1} \mathrm{~s}^{-1}$ ] was calculated from the initial conversion of the alcohol, usually within the first $15 \mathrm{~min}$ of the reaction. Because $\mathrm{Sn}$ is not active for oxidation catalysis, some estimate of surface Pt is needed to calculate a turnover frequency. As a first approximation, we normalized the initial TOF of HDO conversion to the estimated fraction of $\mathrm{Pt}$ atoms that can be exposed to the surface, which is determined from the inverse of surface weighted average metal diameter by TEM ${ }^{49,50}$.

\section{Results}

\subsection{Characterization of bimetallic PtSn catalysts}

The mean particle sizes of bimetallic PtSn catalysts are reported in Table 1. The 
bright field TEM images for $\mathrm{PtSn} / \mathrm{C}$ and $\mathrm{PtSn} / \mathrm{C}-\mathrm{H}$ showed a fairly narrow size distribution of nanoparticles on the carbon support (Figures 1 and 2). Although some large nanoparticles were observed $(\sim 10 \mathrm{~nm})$, the vast majority of particles was in the range of 2 to $5 \mathrm{~nm}$ (Fig. 2). The number average particle diameter of catalysts with different $\mathrm{Pt}$ to $\mathrm{Sn}$ ratio and various treatments ranged from $2.9 \mathrm{~nm}$ to $3.8 \mathrm{~nm}$, as summarized in Table 1 . The similarity of the particle sizes in this study enabled us to eliminate particle size as a factor that might influence the observed catalytic performance. A surface-weighted average metal particle diameter of PtSn bimetallic catalysts is also presented in Table 1. The surface-weighted average diameter was used to estimate the potential fraction of exposed Pt metal sites on the surface, which was subsequently used to calculate a lower bound on the turnover frequency (TOF) and the number of catalytic turnovers. For monometallic Pt catalysts, the fraction of exposed metal atoms, or dispersion, can also be determined by $\mathrm{H}_{2}$ chemisorption. As summarized in Table 1 , the dispersion of $\mathrm{Pt}(\mathrm{H} / \mathrm{Pt})$ was 0.33 and 0.31 for $3 \mathrm{Pt} / \mathrm{C}$ and 3Pt/C-H, respectively. The calculated $\mathrm{Pt}$ surface fraction of $3 \mathrm{Pt} / \mathrm{C}$ and $3 \mathrm{Pt} / \mathrm{C}-\mathrm{H}$, determined from TEM, was 0.20 , which is slightly lower than the dispersion determined by chemisorption. This discrepancy is probably the result of small nanoparticles $(<1 \mathrm{~nm})$ that were not counted by TEM, which is limited by the resolution of method, whereas $\mathrm{H}_{2}$ chemisorption includes all nanoparticles.

The X-ray diffraction patterns of $\mathrm{PtSn} / \mathrm{C}$ are shown in Fig. 3a. The peak at $26.6^{\circ}$ was attributed to graphitic carbon (JCPDS 23-0064) while the peaks at $39.6^{\circ}, 45.9^{\circ}$ and 
67.5 $5^{\circ}$ were attributed to the (111), (200) and (220) features of Pt (JCPDS 04-802). As an increasing amount $\mathrm{Sn}$ was added, there was no obvious shift in the XRD patterns compared to monometallic Pt catalyst (Fig. 3a). Evidently, Pt-Sn alloys were not formed when the bimetallic samples were prepared by $\mathrm{NaBH}_{4}$ reduction, without additional treatment in $\mathrm{H}_{2}$. Because the diffraction patterns of Sn (JCPDS 04-0673), SnO (JCPDS 06-0395) and $\mathrm{SnO}_{2}$ (JCPDS 21-1250) were not observed, we conclude that $\mathrm{Sn}$ species were well dispersed over the carbon support and/or Pt nanoparticles. The XRD patterns of the PtSn/C-H, shown in Fig. 3b, indicate alloy formation from $\mathrm{Pt}$ and $\mathrm{Sn}\left(\mathrm{Pt}_{3} \mathrm{Sn}\right.$ and PtSn) resulting from treatment in $\mathrm{H}_{2}$ at $673 \mathrm{~K}$. With a small amount of added $\mathrm{Sn}$, the Pt (111), (200) and (220) peaks shifted to lower angle for 3Pt1Sn/C-H. In particular, the (220) feature moved from $67.5^{\circ}$ for $3 \mathrm{Pt} / \mathrm{C}-\mathrm{H}$ to $65.9^{\circ}$ for $3 \mathrm{Pt} 1 \mathrm{Sn} / \mathrm{C}-\mathrm{H}$ catalyst, indicating the formation of a $\mathrm{Pt}_{3} \mathrm{Sn}$ alloy (JCPDS 35-1360). Because the XRD patterns exhibited features that appeared between the diffraction patterns of $\mathrm{Pt}$ and $\mathrm{Pt}_{3} \mathrm{Sn}$ alloy, we propose that $3 \mathrm{Pt} 1 \mathrm{Sn} / \mathrm{C}-\mathrm{H}$ contained a mixture of $\mathrm{Pt}, \mathrm{Pt}_{3} \mathrm{Sn}$ and other $\mathrm{Sn}$ species ${ }^{19,21}$. When the ratio of $\mathrm{Sn}$ to $\mathrm{Pt}$ was equal to or greater than one, diffraction features of the 1:1 PtSn alloy were observed. For $3 \mathrm{Pt} 3 \mathrm{Sn} / \mathrm{C}-\mathrm{H}$ and $3 \mathrm{Pt} 6 \mathrm{Sn} / \mathrm{C}-\mathrm{H}$, new peaks appeared at $41.8^{\circ}$ and $44.1^{\circ}$, which were attributed to the PtSn alloy (JCPDS 25-614). The significant difference between the XRD patterns in Fig 3a and Fig 3b clearly demonstrate the importance of $\mathrm{H}_{2}$ treatment at elevated temperature to enhance Pt-Sn interaction and to form Pt-Sn alloy nanoparticles. The crystallite size of the monometallic Pt particles can also be calculated from XRD results using the Scherrer equation. For 3Pt/C and 
3Pt/C-H, the crystallite sizes were estimated to be $4.7 \mathrm{~nm}$ and $5.2 \mathrm{~nm}$, respectively, which were slightly larger than the average diameters evaluated from TEM because the crystallite size determined by XRD is a volume-weighted average diameter ${ }^{49}$ that is usually shifted to higher value. Nevertheless, the size of Pt nanoparticles determined from $\mathrm{H}_{2}$ chemisorption, TEM and XRD was relatively consistent.

To probe the surface composition of the bimetallic nanoparticles, $\mathrm{H}_{2}$ chemisorption and XPS were utilized. The $\mathrm{H} / \mathrm{Pt}$ ratios for bimetallic PtSn catalysts determined by chemisorption are listed in Table 1. For both $\mathrm{PtSn} / \mathrm{C}$ and $\mathrm{PtSn} / \mathrm{C}-\mathrm{H}$, the ratio of adsorbed hydrogen atoms to total platinum atoms decreased significantly, with increasing amounts of $\mathrm{Sn}$. The $\mathrm{H} / \mathrm{Pt}$ ratio of $3 \mathrm{Pt} / \mathrm{C}$ and $3 \mathrm{Pt} / \mathrm{C}-\mathrm{H}$ were 0.33 and 0.31 , whereas the $\mathrm{H} / \mathrm{Pt}$ ratio decreased to 0.11 for $3 \mathrm{Pt} 6 \mathrm{Sn} / \mathrm{C}$ and 0 for $3 \mathrm{Pt} 6 \mathrm{Sn} / \mathrm{C}-\mathrm{H}$. As revealed by TEM, the drop in $\mathrm{H}_{2}$ chemisorption on the samples was not the result of larger particles being formed. Instead, Sn species ( $\mathrm{Sn}$ metal or $\mathrm{Sn}$ oxide) were present on the surfaces of Pt-Sn nanoparticles and block Pt sites from the uptake of hydrogen, a phenomenon that has also been observed by others with bimetallic PtSn catalysts ${ }^{2,5}$.

For $\mathrm{H}_{2}$ chemisorption measurements, the catalysts were first pretreated in $\mathrm{H}_{2}$ at 473 $\mathrm{K}$, which might have altered the structure of $\mathrm{PtSn} / \mathrm{C}$, compared to those prepared only by reduction of $\mathrm{NaBH}_{4}$. To investigate the potential influence of pretreatment during the $\mathrm{H}_{2}$ chemisorption experiment, $3 \mathrm{Pt} 3 \mathrm{Sn} / \mathrm{C}$ was exposed to flowing $\mathrm{H}_{2}$ at $473 \mathrm{~K}$ for $4 \mathrm{~h}$, characterized by XRD and tested in HDO oxidation reaction (the results are presented in Fig. S1). The XRD pattern revealed that the structure of $3 \mathrm{Pt} 3 \mathrm{Sn} / \mathrm{C}-473 \mathrm{H}$ was similar to 
that of $3 \mathrm{Pt} 3 \mathrm{Sn} / \mathrm{C}$ before $\mathrm{H}_{2}$ treatment. No indication of Pt-Sn alloy formation was observed by XRD. In addition, the reaction profile during HDO oxidation over 3Pt3Sn/C was unaffected by the $\mathrm{H}_{2}$ treatment at $473 \mathrm{~K}$ (Fig. S1b and Fig. 4b). We therefore conclude that the $473 \mathrm{~K}$ pretreatment for $\mathrm{H}_{2}$ chemisorption did not significantly influence the morphology of $\mathrm{PtSn} / \mathrm{C}$ in the way that treatment at $673 \mathrm{~K}$ in $\mathrm{H}_{2}$ did.

The XPS analysis of $3 \mathrm{Pt} 3 \mathrm{Sn} / \mathrm{C}$ and $3 \mathrm{Pt} 3 \mathrm{Sn} / \mathrm{C}-\mathrm{H}$ revealed the enrichment of $\mathrm{Sn}$ species on the surface, which is consistent with the $\mathrm{H}_{2}$ chemisorption results. As shown in Table 2, the ratio of $\mathrm{Sn}$ to $\mathrm{Pt}$ was 1.3 and 2.1 for $3 \mathrm{Pt} 3 \mathrm{Sn} / \mathrm{C}$ and $3 \mathrm{Pt} 3 \mathrm{Sn} / \mathrm{C}-\mathrm{H}$, respectively. The increase in the ratio of $\mathrm{Sn}$ to $\mathrm{Pt}$ after $\mathrm{H}_{2}$ treatment may suggest an enhanced interaction of Sn and Pt atoms. The XPS analysis also provides information on the oxidation states of Pt and $\mathrm{Sn}$. The $\mathrm{Pt} 4 \mathrm{f}_{7 / 2}$ and $\mathrm{Sn} 3 \mathrm{~d}_{5 / 2}$ spectra of $3 \mathrm{Pt} 3 \mathrm{Sn} / \mathrm{C}$ and 3Pt3Sn/C-H are shown in Fig. 5, and the fitting results are summarized in Table 2. The Pt $4 \mathrm{f}_{7 / 2}$ features were fitted with two oxidation states: $\mathrm{Pt}(0)$ and $\mathrm{Pt}(\mathrm{II})$ at $\sim 71 \mathrm{eV}$ and $\sim 73$ $\mathrm{eV}$, respectively. The $\mathrm{Sn} 3 \mathrm{~d}_{5 / 2}$ spectra were fitted with $\mathrm{Sn}(0)$ and $\mathrm{Sn}$ (II, IV) at $\sim 486 \mathrm{eV}$ and $\sim 487 \mathrm{eV}$, respectively. Because the difference in the binding energy of $\mathrm{Sn}(\mathrm{II})$ and $\mathrm{Sn}(\mathrm{IV})$ is only $0.2 \mathrm{eV}^{5}$, it was not possible to differentiate between them by curve fitting. Thus, only one peak was fitted in the analysis of the oxidized Sn. For 3Pt3Sn/C, $83 \%$ of the Pt was metallic. Conversely, the majority of Sn (78\%) was oxidized to Sn(II) or $\mathrm{Sn}(\mathrm{IV})$. After the treatment in $\mathrm{H}_{2}(3 \mathrm{Pt} 3 \mathrm{Sn} / \mathrm{C}-\mathrm{H})$, the small contribution from $\mathrm{Pt}(\mathrm{II})$ disappeared so that nearly all of the $\mathrm{Pt}$ was metallic. The metallic $\operatorname{Sn}(0)$ content 
increased from $22 \%$ to $32 \%$ by treatment of the sample in the $\mathrm{H}_{2}$. Evidently, treatment in $\mathrm{H}_{2}$ at $673 \mathrm{~K}$ reduced all of the $\mathrm{Pt}$ but only partially reduced the $\mathrm{Sn}$, which is consistent with results reported by Ruiz-Martínez et al. ${ }^{5}$. The reduction of Pt and Sn oxides at $673 \mathrm{~K}$ in $\mathrm{H}_{2}$ is correlated to the formation Pt-Sn alloy observed by XRD. Chang et al. reported that the reduction of bimetallic Pt-Sn occurs below $600 \mathrm{~K}$ while the reduction of Sn oxide alone requires over $700 \mathrm{~K}^{20}$. Because the catalysts were treated in $\mathrm{H}_{2}$ at $673 \mathrm{~K}$, it is quite likely that $\mathrm{Sn}$ species adjacent to Pt were reduced to form a Pt-Sn alloy whereas isolated Sn oxide on the support remained unreduced.

Both the XRD and XPS results suggest that treatment in $\mathrm{H}_{2}$ at $673 \mathrm{~K}$ promoted the interaction of $\mathrm{Pt}$ and $\mathrm{Sn}$ atoms and the formation of alloy nanoparticles. To further investigate the composition of catalysts, $\mathrm{PtSn} / \mathrm{C}$ and $\mathrm{PtSn} / \mathrm{C}-\mathrm{H}$ were examined by EDS in the electron microscope before and after thermal treatment in $\mathrm{H}_{2}$. The composition of individual particles was determined with an EDS spot size of approximately $100 \mathrm{~nm}^{2}$, whereas the overall composition was measured by EDS using a $\sim 2500 \mathrm{~nm}^{2}$ probe size. Figure 6 and Table 3 present the regions analyzed by EDS and the resulting metal compositions of $3 \mathrm{Pt} 3 \mathrm{Sn} / \mathrm{C}$ and $3 \mathrm{Pt} 3 \mathrm{Sn} / \mathrm{C}-\mathrm{H}$. Areas that contain relatively large nanoparticles (a1, a2, a3, a4, b1, b2, b5) and small nanoparticles (a5, b3, b4) were measured. The overall composition evaluated by EDS of $3 \mathrm{Pt} 3 \mathrm{Sn} / \mathrm{C}$ and $3 \mathrm{Pt} 3 \mathrm{Sn} / \mathrm{C}-\mathrm{H}$ confirmed an atomic ratio of Pt:Sn close to unity, which is consistent with the nominal atomic ratio of the sample. Individual nanoparticles examined with the small probe size revealed a wide distribution of metal compositions on $3 \mathrm{Pt} 3 \mathrm{Sn} / \mathrm{C}$. For example, the metal 
in region a3 (Fig. 6a) was nearly all Pt whereas the metal in region a5 (Fig. 6a) was mostly Sn. After treatment of the sample in $\mathrm{H}_{2}$ at $673 \mathrm{~K}$, the distribution of metals appeared to be more uniform. As shown in Fig. 6b and Table 3, the relative percentages of $\mathrm{Pt}$ and $\mathrm{Sn}$ were close to 50/50 for both large or small nanoparticles on $3 \mathrm{Pt} 3 \mathrm{Sn} / \mathrm{C}-\mathrm{H}$. Similar results were also observed on 3Pt6Sn/C and 3Pt6Sn/C-H (Fig. S2 and Table S2). In an effort to quantify the distribution of the particle compositions for bimetallic PtSn catalyst before and after thermal treatment in $\mathrm{H}_{2}, 20$ nanoparticle regions for each sample were analyzed and the compositions are listed in Table S3. For both 3Pt3Sn/C and $3 \mathrm{Pt} 6 \mathrm{Sn} / \mathrm{C}$, the standard deviation in the measured Pt content was $20 \%$ and $28 \%$, respectively, indicating a fairly broad distribution of compositions. After the treatment in $\mathrm{H}_{2}$ at $673 \mathrm{~K}$, however, the standard deviation decreased to $6 \%$ and $7 \%$, respectively, indicating a more uniform distribution in particle composition. The broad distribution in composition of $\mathrm{PtSn} / \mathrm{C}$ suggests that the $\mathrm{Sn}$ species were dispersed randomly on both the carbon support and on the platinum nanoparticles. After thermal treatment in $\mathrm{H}_{2}$, the interaction between $\mathrm{Pt}$ and $\mathrm{Sn}$ was enhanced and the resulting bimetallic nanoparticles were fairly uniform in composition.

Additional characterization by STEM-EDS was also performed. Figure 7 shows the STEM-EDS line-scan results of $3 \mathrm{Pt} 3 \mathrm{Sn} / \mathrm{C}$ and $3 \mathrm{Pt} 3 \mathrm{Sn} / \mathrm{C}-\mathrm{H}$ with the scanning region indicated by the red line. For 3Pt3Sn/C, the Pt was easily detected by EDS. Although Sn signals were also observed, they were less intense and appeared to be dispersed more evenly along the scan line. This result is consistent with the idea that Pt nanoparticles 
were formed during the $\mathrm{NaBH}_{4}$ reduction step and the $\mathrm{Sn}$ was deposited on both the $\mathrm{Pt}$ and carbon support. After the thermal treatment in $\mathrm{H}_{2}, \mathrm{Sn}$ and $\mathrm{Pt}$ appear together in the EDS line scan, as shown in Fig. 7b, and the intensities of metal EDS signals were similar, which is consistent with the nominal 1:1 molar ratio of Pt:Sn in the sample.

The nature of the catalyst was different in the presence of excess Sn relative to Pt. The major diffraction features of 3Pt6Sn/C-H are attritbuted to the equimolar PtSn alloy (Fig 3b). The excess Sn appears to be associated with the bimetallic nanoparticles since single particle EDS revealed the appropriate composition of Pt and Sn. The micrographs in Fig. 8 reveal a core-shell structure of the bimetallic particles on this sample. It needs to be mentioned that no core-shell structures were observed for the other bimetallic PtSn catalysts. The contrast differences in bright field TEM (Fig. 8a) and dark field STEM (Fig. 8b) suggest the Pt or PtSn alloy was present in the core of the particles whereas amorphous Sn oxide was the primary component of the shell ${ }^{36}$. This core-shell model explains why the $\mathrm{H} / \mathrm{Pt}$ ratio of $3 \mathrm{Pt} 6 \mathrm{Sn} / \mathrm{C}-\mathrm{H}$ measured by $\mathrm{H}_{2}$ chemisorption was below the detection limit. The Pt sites capable of chemisorbing $\mathrm{H}$ atoms were covered by a Sn shell, likely $\mathrm{SnO}_{x}$, that is not able to chemisorb $\mathrm{H}_{2}$.

In summary, the $\mathrm{PtSn} / \mathrm{C}$ and $\mathrm{PtSn} / \mathrm{C}-\mathrm{H}$ have different compositions and structures resulting from overall metal loading and thermal treatment in $\mathrm{H}_{2}$. Without the $\mathrm{H}_{2}$ treatment, negligible alloy formation was observed. Evidently, the Sn species were well dispersed on the support and the surfaces of Pt nanoparticles. After the thermal treatment in $\mathrm{H}_{2}$, the presence of Pt-Sn alloys was detected by XRD and STEM-EDS and 
the bimetallic particles were more uniform in composition. For 3Pt6Sn/C-H containing excess $\mathrm{Sn}$ relative to $\mathrm{Pt}$, a core-shell nanoparticle was observed, which was composed of a Pt or Pt-Sn alloy core surrounded by $\mathrm{SnO}_{x}$ species shell that could not chemisorb dihydrogen.

\subsection{HDO oxidation over bimetallic PtSn catalysts}

The differences in structure and composition of the PtSn/C and PtSn/C-H catalysts were accompanied by differences in catalyst performance in the selective oxidation of 1,6-hexanediol. The turnover frequencies (TOF) and number of turnovers were normalized by the Pt content in the sample and the fraction of surface atoms calculated from the surface weighted average diameter from TEM (Table 1). The reactivity results for the series of bimetallic PtSn catalysts are shown in Fig. 4 and Tables 4 and 5. The performance of the bimetallic PtSn catalysts without $\mathrm{H}_{2}$ treatment will be discussed first. As indicated in Table 4, the conversion of HDO at 15 min increased only slightly with the addition of $\mathrm{Sn}$, from $20 \%$ for $3 \mathrm{Pt} / \mathrm{C}$ to $26 \%$ for $3 \mathrm{Pt} 6 \mathrm{Sn} / \mathrm{C} \mathrm{CIN}$. These results correspond to a slight increase in TOF, from $0.44 \mathrm{~s}^{-1}$ for $3 \mathrm{Pt} / \mathrm{C}$ to $0.50 \mathrm{~s}^{-1}$ for $3 \mathrm{Pt} 6 \mathrm{Sn} / \mathrm{C}$. The conversion of HDO after $4 \mathrm{~h}$ of reaction over the PtSn/C exhibited a similar trend. For example, the $4 \mathrm{~h}$ conversion of $\mathrm{HDO}$ was $60 \%$ for $3 \mathrm{Pt} 6 \mathrm{Sn} / \mathrm{C}$ compared to $47 \%$ for 3Pt/C. The number of turnovers, which is based on the conversion after $4 \mathrm{~h}$, was the highest for $3 \mathrm{Pt} 3 \mathrm{Sn} / \mathrm{C}$ and was 1.6 times that of monometallic Pt/C. Evidently, the addition of Sn had a modest promotional influence on the initial activity and the number 
of turnovers after $4 \mathrm{~h}$ of reaction, and the deactivation behavior of the bimetallic PtSn catalysts was comparable to the monometallic Pt catalyst, as shown in Fig. 4b. The product distributions at relatively low conversion $(\sim 20 \%)$ and higher conversion $(\sim 50 \%)$ listed in Tables 4 and 5 revealed no significant change with Sn loading.

The catalysts were also evaluated after thermal treatment in $\mathrm{H}_{2}$ to test the effect of alloy formation on reactivity. As discussed above, XRD revealed that 3Pt1Sn/C-H contains $\mathrm{Pt}_{3} \mathrm{Sn}$ alloy whereas $3 \mathrm{Pt} 3 \mathrm{Sn} / \mathrm{C}-\mathrm{H}$ and $3 \mathrm{Pt} 6 \mathrm{Sn} / \mathrm{C}-\mathrm{H}$ contains the $\mathrm{PtSn}$ alloy. As shown in Table 4, the initial conversion of HDO on monometallic 3Pt/C-H after $15 \mathrm{~min}$ was $22 \%$, which is approximately the same as untreated $3 \mathrm{Pt} / \mathrm{C}$ catalyst $(20 \%)$. The initial conversion of HDO decreased significantly when Sn was added to the catalyst and subsequently treated in $\mathrm{H}_{2}$ to form alloy nanoparticles. The conversion after $15 \mathrm{~min}$ was $14 \%, 12 \%$ and $6 \%$ for $3 \mathrm{Pt} 1 \mathrm{Sn} / \mathrm{C}-\mathrm{H}, 3 \mathrm{Pt} 3 \mathrm{Sn} / \mathrm{C}-\mathrm{H}$ and $3 \mathrm{Pt} 6 \mathrm{Sn} / \mathrm{C}-\mathrm{H}$, respectively. Although the initial activity decreased with $\mathrm{Sn}$ addition, the rate was recovered during the HDO oxidation reaction. As shown in Fig. 4c, the rate of reaction increased over $3 \mathrm{Pt} 3 \mathrm{Sn} / \mathrm{C}-\mathrm{H}$ and $3 \mathrm{Pt} 6 \mathrm{Sn} / \mathrm{C}-\mathrm{H}$ in the first $30 \mathrm{~min}$ of reaction and then gradually decreased. After $4 \mathrm{~h}$ of reaction, the conversion and number of turnovers for the $\mathrm{PtSn} / \mathrm{C}-\mathrm{H}$ bimetallic catalysts were ultimately higher than those determined with the monometallic 3Pt/C-H. The number of turnovers (after $4 \mathrm{~h}$ ) was $2.0 \times 10^{3}$ for 3Pt3Sn/C-H, which is twice that for 3Pt/C-H. The product distribution at low and high conversion is summarized in Tables 4 and 5. As observed with non-alloyed $\mathrm{PtSn} / \mathrm{C}$ catalysts, no significant change in product distribution was observed with the PtSn/C-H 
catalysts.

\subsection{Characterization of $\mathrm{PtSn/C-H}$ after reaction}

The initially low rate of conversion of HDO over the PtSn/C-H catalysts relative to a monometallic Pt catalyst indicates an induction period for catalyst activity followed by the usual deactivation. A change in the active sites during reaction can be ascribed to sintering ${ }^{51,52}$, leaching ${ }^{51,53}$, over-oxidation ${ }^{54}$, adsorption of by-products ${ }^{46,51,55-64}$ and modification of the nanoparticle composition or structure ${ }^{15,25,36}$. To probe the potential influence of metal leaching, fresh 3Pt3Sn/C-H and used 3Pt3Sn/C-H-R catalysts were analyzed by ICP-AES and the elemental analysis results are summarized in Table 6 . As a reference, the nominal molar loading of each metal was $0.15 \mathrm{mmol} / \mathrm{g}$. As indicated in Table 6, the molar loading of Pt and Sn measured by ICP-AES was close to the nominal value for the fresh catalyst. Although molar loading of Pt and Sn was slightly lower on the catalyst recovered from $4 \mathrm{~h}$ HDO oxidation, the molar ratio of $\mathrm{Pt}$ to $\mathrm{Sn}$ remained constant at 1.2. The recovered reaction medium was also tested for leached metals after $4 \mathrm{~h}$ of reaction. The concentration of $\mathrm{Pt}$ and $\mathrm{Sn}$ were below $6.3 \mathrm{ppm}$ (the detection limit of ICP-AES), confirming less than $2 \%$ of available Pt or Sn leached into the solution. We attribute the slight decrease of Pt and Sn loading on the used catalyst to adsorbed species on the solid rather than the leaching of Pt and Sn into the solution, a conclusion also reached by Wörz et al. ${ }^{65}$.

The 3Pt3Sn/C-H-R and 3Pt6Sn/C-H-R catalysts collected after $4 \mathrm{~h}$ of reaction were 
further analyzed by TEM to determine whether or not sintering of nanoparticles occurred during the reaction. The TEM images of the used catalysts and corresponding particle size distributions are shown in Fig. S3 and the statistical analyses of the nanoparticle sizes are presented in Table 1. The mean particle diameters (determined from a Cauchy-Lorentz distribution) of 3Pt3Sn/C-H-R and 3Pt6Sn/C-H-R was $3.6 \pm 0.9$ $\mathrm{nm}$ and $3.1 \pm 0.9 \mathrm{~nm}$, respectively, which are quite similar to the mean diameters of the catalysts prior to reaction $(3.8 \pm 1.0 \mathrm{~nm}$ and $3.2 \pm 0.9 \mathrm{~nm}$, respectively). Likewise, the surface average diameters, which are related to the fractions of exposed metal sites, are also similar for PtSn/C-H and PtSn/C-H-R catalysts. Prior work by Ide et al. has also shown that a monometallic Pt/C catalyst does not sinter during the selective oxidation of alcohols under similar conditions ${ }^{46}$.

To investigate the oxidation state of $\mathrm{Pt}$ and $\mathrm{Sn}$ after reaction, the $3 \mathrm{Pt} 3 \mathrm{Sn} / \mathrm{C}-\mathrm{H}-\mathrm{R}$ collected after $4 \mathrm{~h}$ of HDO oxidation was analyzed by XPS and compared to 3Pt3Sn/C-H prior to reaction. The Pt $4 \mathrm{f}_{7 / 2}$ and $\mathrm{Sn} 3 \mathrm{~d}_{5 / 2}$ core level spectra of 3Pt3Sn/C-H-R are shown in Figs. 5 e,f and the analysis of the spectra is summarized in Table 2. For both 3Pt3Sn/C-H and 3Pt3Sn/C-H-R, the Pt detected by XPS remained in the metallic state. Evidently, the Pt sites were not deactivated by over-oxidation during the reaction. Since the Pt sites are believed to be the active sites for $\beta$-hydrogen elimination, which is proposed to be a kinetically significant step in the alcohol oxidation reaction ${ }^{44}$, we do not suspect that over-oxidation of Pt sites in the presence of Sn was the reason for the low initial activity of the hydrogen-treated bimetallic catalysts. 
In contrast to $\mathrm{Pt}$, the percentage of oxidized $\mathrm{Sn}$ increased from $68 \%$ for $3 \mathrm{Pt} 3 \mathrm{Sn} / \mathrm{C}-\mathrm{H}$ catalyst to $87 \%$ for $3 \mathrm{Pt} 3 \mathrm{Sn} / \mathrm{C}-\mathrm{H}-\mathrm{R}$. The small fraction of remaining metallic $\mathrm{Sn}$ is speculated to remain in the alloy phase. We suspect the oxidation of $\mathrm{Sn}$ to be accompanied by compositional and structural change of nanoparticles, which might account for the induction period observed with the alloy catalyst.

For fresh 3Pt3Sn/C-H, TEM-EDS shows that nanoparticles have a relatively uniform composition of metals and Pt-Sn alloy formation was detected by XRD and STEM-EDS. After 15 min of reaction, the relatively uniform composition of Pt and Sn in 1:1 ratio in the individual nanoparticles was maintained, as indicated in Table 3 . The statistical analysis of EDS results of twenty regions of 3Pt3Sn/C-H-R (after $15 \mathrm{~min}$ ) is presented in Table S4 and reveals a standard deviation of 15\% for the Pt and Sn content, which is larger than the observed deviation of the Pt and Sn content of the fresh catalyst (7\%). The larger deviation in particle composition of a used catalyst (after 15 min of reaction) suggests a change in the composition of the nanoparticles. After $4 \mathrm{~h}$ of reaction, the compositional and structural changes of $3 \mathrm{Pt} 3 \mathrm{Sn} / \mathrm{C}-\mathrm{H}$ are more evident. The compositional variations presented in Table 3 and the statistical analysis of 20 regions of nanoparticles in Table. S4 both confirm a broader distribution of metal composition of the used catalyst compared to those prior to reaction. The STEM-EDS results in Figures $7 \mathrm{c}$ and $\mathrm{d}$ show that although Pt and Sn appear together in the same particles, the relative intensity of the Sn contribution relative to $\mathrm{Pt}$ decreased at longer reaction time.

The 3Pt3Sn/C-H-R catalyst (after $15 \mathrm{~min}$ and $4 \mathrm{~h}$ of reaction) was also interrogated 
by XRD. The XRD patterns of 3Pt3Sn/C-H-R and 3Pt3Sn/C-H in Fig. 9 indicate a significant decrease in the peaks attributed to PtSn alloy as a result of HDO oxidation reaction. Although the XRD indicates that dealloying of $\mathrm{Pt}$ and $\mathrm{Sn}$ occurred during reaction, no XRD peaks corresponding to Sn or Sn oxides were observed. Evidently, dealloyed Sn species remained well dispersed on the carbon support or Pt surface, since leaching of Sn was not observed. Evidence from TEM, XPS and XRD indicates that alloyed PtSn nanoparticles phase-separated under HDO oxidation conditions and formed a highly dispersed Sn oxide phase on the support.

The 3Pt6Sn/C-H, which is proposed to have a $\mathrm{SnO}_{\mathrm{x}} @ \mathrm{PtSn}$ alloy core-shell structure, is a unique case. The reaction profile in Fig. 8 shows the longest induction time for 3Pt6Sn/C-H and the catalyst had an $\mathrm{H} / \mathrm{Pt}$ ratio of 0 (Table 1), indicating that initially all of the Pt was covered. Thus, the increase in activity observed during the first 30 min of reaction suggests that active Pt surface sites were recovered during the reaction. To study the change during the reaction, the $3 \mathrm{Pt} 6 \mathrm{Sn} / \mathrm{C}-\mathrm{H}-\mathrm{R}$, which was collected after $4 \mathrm{~h}$ of reaction, was characterized by TEM and EDS. The TEM images and the regions for EDS analysis of the used catalyst are shown in Figures S3 and S4, respectively. The shell surrounding the core of Pt or PtSn alloy revealed in Fig. 8 has disappeared, suggesting the migration of the $\mathrm{SnO}_{\mathrm{x}}$ shell under reaction conditions, which explains the recovery of HDO oxidation activity during aqueous phase reaction. As discussed for 3Pt3Sn/C-H, the standard deviation of the individual particle compositions of 3Pt6Sn/C-H increased significantly after reaction, which is consistent 
with a compositional change of the catalyst during reaction.

\section{Discussion}

A significant structural and compositional change of PtSn bimetallic catalyst was observed after hydrogen treatment and oxidation of HDO. Based on the extensive characterization including (S)TEM, EDS, XRD, ICP-AES and XPS, we propose a model for the evolution of $\mathrm{PtSn} / \mathrm{C}, \mathrm{PtSn} / \mathrm{C}-\mathrm{H}$ and $\mathrm{PtSn} / \mathrm{C}-\mathrm{H}-\mathrm{R}$ catalysts, as shown in Scheme 1. For the $\mathrm{PtSn} / \mathrm{C}$ catalysts prepared by $\mathrm{NaBH}_{4}$ reduction, $\mathrm{SnO}_{\mathrm{x}}$ species were well dispersed on the carbon support and on Pt nanoparticles (Scheme 1a), with negligible formation of Pt-Sn alloy. After the $\mathrm{H}_{2}$ treatment at $673 \mathrm{~K}$, Pt-Sn alloy particles were observed on PtSn/C-H (Scheme 1b), which could be explained by the enhanced interaction between adjacent $\mathrm{Pt}$ and $\mathrm{Sn}$ species in $\mathrm{H}_{2}$ under high temperature 20,66. During the oxidation of HDO in liquid water over $\mathrm{PtSn} / \mathrm{C}-\mathrm{H}$, however, a phase segregation of the Pt-Sn alloy particles occurred (Scheme 1a), which was also observed by Michalak et al. in CO oxidation at around $500 \mathrm{~K}$ over a PtSn bimetallic catalyst ${ }^{12}$.

To study the activity of different catalysts, a comparison of turnover frequencies is commonly employed. The ambiguity of this comparison arises from a lack of clarity regarding the active sites available for reaction. Because a monometallic Sn catalyst showed no activity in alcohol oxidation, we conclude that the exposed Pt atoms are the active sites. The observed changes in the structure and composition of the PtSn bimetallic catalysts during the reaction prevented the common use of $\mathrm{H}_{2}$ chemisorption 
as a method to quantify the active Pt sites. Thus, as a first approximation, we estimated the fraction of active sites to be the inverse of the surface-weighted average diameter of Pt nanoparticles determined from TEM (Table 1), assuming that the fraction of Pt sites that can be eventually exposed to the surface is the same as the fraction of surface atoms from TEM. This assumption is reasonable for both $\mathrm{PtSn} / \mathrm{C}$ and $\mathrm{PtSn} / \mathrm{C}-\mathrm{H}$ catalysts for the following reasons. First, the $\mathrm{SnO}_{\mathrm{x}}$ species are well dispersed and mobile on $\mathrm{PtSn} / \mathrm{C}$, so the nanoparticles observed by TEM are likely composed primarily of Pt. For alloyed particles in $\mathrm{PtSn} / \mathrm{C}-\mathrm{H}$, the fraction of exposed Pt and the fraction of exposed metal $(\mathrm{Pt}+\mathrm{Sn})$ are assumed to be similar. Finally, there was a negligible change in particle size during reaction (Table 1).

The impact of adding Sn to Pt on the catalysis of HDO oxidation depends on the structure of the catalyst. Whereas addition of $\mathrm{Sn}$ to Pt modestly increased the initial activity of $\mathrm{PtSn} / \mathrm{C}$ catalysts relative to $\mathrm{Pt}$, thermal treatment of those same catalysts in $\mathrm{H}_{2}$ to produce $\mathrm{PtSn} / \mathrm{C}-\mathrm{H}$ actually decreased the initial activity relative to $\mathrm{Pt}$. The results from characterization suggest that the $\mathrm{Pt}-\mathrm{SnO}_{\mathrm{x}}$ interface in $\mathrm{PtSn} / \mathrm{C}$ promotes oxidation activity while alloying Sn with Pt inhibits activity. Although the exact relationship between the structure and oxidation activity of PtSn bimetallic catalysts is still not clear, the modest promotional effect of the $\mathrm{Pt}-\mathrm{SnO}_{\mathrm{x}}$ interface might be related to a change of exposed Pt ensembles ${ }^{67}$, the introduction of $\mathrm{O}_{2}$ adsorption sites ${ }^{12}$ and/or the enhanced ability to remove strongly-adsorbed species ${ }^{28,29}$. As discussed in the literature, changes in electron density ${ }^{19,26}$ and/or modified lattice spacing ${ }^{14,33,35}$ upon Pt-Sn alloy 
formation might account for the negative impact on activity. Although the initial rate over the alloyed nanoparticles on $\mathrm{PtSn} / \mathrm{C}-\mathrm{H}$ was low, the activity was recovered throughout the initial stages of the reaction $(1 \mathrm{~h})$. Accordingly, recovery of activity was accompanied by dealloying of nanoparticles on $\mathrm{PtSn} / \mathrm{C}-\mathrm{H}$ and the subsequent formation of $\mathrm{SnO}_{\mathrm{x}}$ near the active Pt particles.

\section{Conclusions}

Bimetallic PtSn/C catalysts, which were initially reduced with sodium borohydride, formed nanoparticles of $\mathrm{Pt}$ and a dispersed phase of $\mathrm{SnO}_{\mathrm{x}}$. The presence of $\mathrm{SnO}_{\mathrm{x}}$ promoted the turnover frequency of 1,6-hexanediol oxidation, presumably a consequence of the $\mathrm{Pt}_{-} \mathrm{SnO}_{\mathrm{x}}$ interface. Treatment of a $\mathrm{PtSn} / \mathrm{C}$ catalyst in $\mathrm{H}_{2}$ at $673 \mathrm{~K}$ resulted in the formation of alloyed Pt-Sn nanoparticles that were initially less active than Pt for 1,6-hexanediol oxidation. During the alcohol oxidation reaction over the alloyed catalysts, the $\mathrm{Sn}$ dealloyed from the nanoparticles and formed $\mathrm{SnO}_{\mathrm{x}}$ species, leading to the recovery of the oxidation activity with time in the reactor. This work presents evidence for severe restructuring of PtSn catalysts under the relatively mild conditions of aqueous-phase alcohol oxidation and illustrates the importance of characterizing the structure and composition of bimetallic catalysts after exposure to reactive environments.

\section{Acknowledgements}


The authors would like to acknowledge Dr. Dmitry Pestov in the Nanomaterials Characterization Center at Virginia Commonwealth University as well as Richard White in the Nanoscale Materials Characterization Facility at the University of Virginia. This material was based upon the work supported by the National Science Foundation under award number EEC-0813570. Helpful discussions with Nicholas Kaylor, Dr. Matthew Ide, Dr. Hien Pham and Professor Matthew Neurock are also acknowledged. 


\section{References:}

1 S. Zhang, X. Duan, L. Ye, H. Lin, Z. Xie and Y. Yuan, Catal. Today, 2013, 215, $260-266$.

2 F. Coloma, A. Sepúlveda-Escribano, J.L.G. Fierro and F. Rodríguez-Reinoso, Appl. Catal. A Gen., 1996, 136, 231-248.

3 F. Coloma, A. Sepúlveda-Escribano, J.L.G. Fierro and F. Rodríguez-Reinoso, Appl. Catal. A Gen., 1996, 148, 63-80.

4 D. I. Jerdev, A. Olivas and B. E. Koel, J. Catal., 2002, 205, 278-288.

5 J. Ruiz-Martínez, A. Sepúlveda-Escribano, J. A. Anderson and F. Rodríguez-Reinoso, Catal. Today, 2007, 123, 235-244.

6 S. N. Coman, V. I. Parvulescu, M. De Bruyn, D. E. De Vos and P. A. Jacobs, J. Catal., 2002, 206, 218-229.

7 V. Shashikala, H. Jung, C. Shin, H. Koh and K. Jung, Catal. Letters, 2013, 143, $651-656$.

8 S. A. Bocanegra, S. R. de Miguel, I. Borbath, J. L. Margitfalvi and O. A. Scelza, J. Mol. Catal. A Chem., 2009, 301, 52-60. 
9 G. J. Siri, J. M. Ramallo-López, M. L. Casella, J. L. G. Fierro, F. G. Requejo and O. A. Ferretti, Appl. Catal. A Gen., 2005, 278, 239-249.

10 G. J. Arteaga, J. A. Anderson and C. H. Rochester, J. Catal., 1999, 187, 219-229.

11 F. Epron, C. Carnevillier and P. Marécot, Appl. Catal. A Gen., 2005, 295, $157-169$.

12 W. D. Michalak, J. M. Krier, S. Alayoglu, J.-Y. Shin, K. An, K. Komvopoulos, Z. Liu and G. A. Somorjai, J. Catal., 2014, 312, 17-25.

13 J. L. Margitfalvi, I. Borbáth, K. Lázár, E. Tfirst, A. Szegedi, M. Hegedüs and S. Gőbölös, J. Catal., 2001, 203, 94-103.

14 Y. Ishikawa, M. S. Liao and C. R. Cabrera, Surf. Sci., 2000, 463, 66-80.

15 S. Biallozor, A. Kupniewska and V. Jasulaitene, Fuel Cells, 2003, 3, 8-14.

16 W. J. Zhou, B. Zhou, W. Z. Li, Z. H. Zhou, S. Q. Song, G. Q. Sun, Q. Xin, S. Douvartzides, M. Goula and P. Tsiakaras, J. Power Sources, 2004, 126, 16-22.

17 J. M. Léger, S. Rousseau, C. Coutanceau, F. Hahn and C. Lamy, Electrochim. Acta, 2005, 50, 5118-5125.

18 A. O. Neto, M. Linardi and E. V. Spinacé, Ionics, 2006, 12, 309-313. 
19 J. H. Kim, S. M. Choi, S. H. Nam, M. H. Seo, S. H. Choi and W. B. Kim, Appl. Catal. B Environ., 2008, 82, 89-102.

20 Y. W. Chang, C. W. Liu, Y. C. Wei and K. W. Wang, Electrochem. Commun., 2009, 11, 2161-2164.

21 E. Antolini and E. R. Gonzalez, Electrochim. Acta, 2010, 55, 6485-6490.

22 D. R. M. Godoi, J. Perez and H. M. Villullas, J. Power Sources, 2010, 195, 3394-3401.

23 W. Z. Hung, W. H. Chung, D. S. Tsai, D. P. Wilkinson and Y. S. Huang, Electrochim. Acta, 2010, 55, 2116-2122.

24 E. Antolini, Int. J. Hydrogen Energy, 2011, 36, 11043-11047.

25 C. W. Liu, Y. W. Chang, Y. C. Wei and K. W. Wang, Electrochim. Acta, 2011, 56, 2574-2581.

26 X. Wang, H. Xue, L. Yang, H. Wang, P. Zang, X. Qin, Y. Wang, Y. Ma, Q. Wu and Z. Hu, Nanotechnology, 2011, 22, 395-401.

27 Y. Wang, S. Song, G. Andreadis, H. Liu and P. Tsiakaras, J. Power Sources, 2011, 196, 4980-4986. 
28 F. L. S. Purgato, S. Pronier, P. Olivi, A. R. De Andrade, J. M. Léger, G. Tremiliosi-Filho and K. B. Kokoh, J. Power Sources, 2012, 198, 95-99.

29 S. G. Ramos, A. Calafiore, A. R. Bonesi, W. E. Triaca, A. M. Castro Luna, M. S. Moreno, G. Zampieri and S. Bengio, Int. J. Hydrogen Energy, 2012, 37, $14849-14853$.

30 S. Beyhan, J. M. Léger and F. Kadirgan, Appl. Catal. B Environ., 2013, 130-131, $305-313$.

31 A. M. Castro Luna, A. R. Bonesi, M. S. Moreno, G. Zampieri, S. Bengió and W. E. Triaca, Int. J. Hydrogen Energy, 2014, 39, 8690-8696.

32 B. Ruiz-Camacho, H. H. R. Santoyo, J. M. Medina-Flores and O. Álvarez-Martínez, Electrochim. Acta, 2014, 120, 344-349.

33 D. Loffreda, C. Michel, F. Delbecq and P. Sautet, J. Catal., 2013, 308, 374-385.

34 N. Homs, J. Llorca, P. Ramírez de la Piscina, F. Rodríguez-Reinoso, A. Sepúlveda-Escribano and J. Silvestre-Albero, Phys. Chem. Chem. Phys., 2001, 3, $1782-1788$.

35 C. Panja, N. Saliba and B. E. Koel, Surf. Sci., 1998, 395, 248-259.

36 F. Coloma, J. Llorca, N. Homs, P. Ramírez de la Piscina, F. Rodríguez-Reinoso and A. Sepúlveda-Escribano, Phys. Chem. Chem. Phys., 2000, 2, 3063-3069. 
37 R. L. Myers, The 100 Most Important Chemical Compounds: A Reference Guide, Greenwood Press, 2007.

38 M. H. Thiemens and W. C. Trogler, Science, 1991, 251, 932-934.

39 B. G. Hermann, K. Blok and M. K. Patel, Environ. Sci. Technol., 2007, 41, $7915-7921$.

$40 \quad$ K. Sato, Science, 1998, 281, 1646-1647.

41 T. Buntara, S. Noel, P. H. Phua, I. Melián-Cabrera, J. G. de Vries and H. J. Heeres, Angew. Chem. Int. Ed. Engl., 2011, 50, 7083-7087.

42 T. Wang, M. W. Nolte and B. H. Shanks, Green Chem., 2014, 16, 548.

43 S. E. Davis, M. S. Ide and R. J. Davis, Green Chem., 2013, 15, 17.

44 M. S. Ide and R. J. Davis, J. Catal., 2013, 308, 50-59.

45 B. N. Zope, S. E. Davis and R. J. Davis, Top. Catal., 2012, 55, 24-32.

46 M. S. Ide, D. D. Falcone and R. J. Davis, J. Catal., 2014, 311, 295-305.

47 J. J. Yeh and I. Lindau, At. Data Nucl. Data Tables, 1985, 32, 1-155.

48 B. Maier, C. Dietrich and J. Büchs, Food Bioprod. Process., 2001, 79, 107-113. 
49 W. Pabst and E. Gregorova, Characterization of particles and particle sustems, ICT Prague, 2007, 1-122.

$50 \quad$ M. Boudart, J. Catal., 1975, 39, 44-52.

51 T. Mallat and A. Baiker, Catal. Today, 1994, 19, 247-284.

52 Y. Schuurman, B. F. M. Kuster, K. van der Wiele and G. B. Marin, Appl. Catal. A Gen., 1992, 89, 47-68.

53 F. R. Venema, J. A. Peters and H. van Bekkum, J. Mol. Catal., 1992, 77, 75-85.

54 A. P. Markusse, B. F. M. Kuster, D. C. Koningsberger and G. B. Marin, Catal. Letters, 1998, 55, 141-145.

55 T. Mallat and A. Baiker, Chem. Rev., 2004, 104, 3037-3058.

56 M. Mavrikakis and M. A. Barteau, J. Mol. Catal. A Chem., 1998, 131, 135-147.

57 M. Hronec, Z. Cvengrosova, J. Tuleja and J. Ilavsky, New Developments in Selective Oxidation, Elsevier, 1990, vol. 55.

58 T. Mallat, Z. Bodnar and A. Baiker, Stud. Surf. Sci. Catal., 1993, 78, 377-384.

59 T. Mallat, Z. Bodnar, M. Maciejewski and A. Baker, Stud. Surf. Sci. Catal., 1994, 82, 561 . 
60 T. Mallat, Z. Bodnar,C. Brönnimann and A. Baiker, Stud. Surf. Sci. Catal., 1994, 88, 385-392.

61 J. Bonello, E. C. Sykes, R. Lindsay, F. Williams, A. Santra and R. Lambert, Surf. Sci., 2001, 482-485, 207-214.

62 T. Mallat, Z. Bodnar and A. Baiker, Preprints-American Chemical Society. Division of Petroleum Chemistry, 1992, 37, 1151-1157.

63 J. Nie, J. Xie and H. Liu, J. Catal., 2013, 301, 83-91.

64 S. Tan, J. R. Monnier and C. T. Williams, Top. Catal., 2012, 55, 512-517.

65 N. Wörz, a. Brandner and P. Claus, J. Phys. Chem. C, 2010, 114, 1164-1172.

66 G. Neri, G. Rizzo, A. S. Arico', C. Crisafulli, L. De Luca, A. Donato, M. G. Musolino and R. Pietropaolo, Appl. Catal. A Gen., 2007, 325, 15-24.

67 M. Neurock, M. Janik and A. Wieckowski, Faraday Discuss., 2009, 140, 363-378. 


\section{TABLES AND FIGURES}

Table 1. Summary of results from $\mathrm{H}_{2}$ chemisorption and electron microscopy of carbon supported bimetallic PtSn catalysts.

\begin{tabular}{|c|c|c|c|c|c|c|}
\hline Catalysts & $\begin{array}{c}\mathrm{Pt}^{\mathrm{a}} \\
(\mathrm{wt} \%)\end{array}$ & $\begin{array}{c}\mathrm{Sn}^{\mathrm{a}} \\
(\mathrm{wt} \%)\end{array}$ & $\mathrm{H} / \mathrm{Pt}^{\mathrm{b}}$ & $\begin{array}{l}\text { Avg diameter }{ }^{\mathrm{c}} \\
(\mathrm{nm})\end{array}$ & $\begin{array}{l}\text { Surface-weighted } \\
\text { Avg diameter }^{\mathrm{d}}(\mathrm{nm})\end{array}$ & $\begin{array}{c}\text { Fraction of } \\
\text { surface atoms }^{\mathrm{e}}\end{array}$ \\
\hline $3 \mathrm{Pt} / \mathrm{C}^{\mathrm{f}}$ & 3.0 & - & 0.33 & $3.8 \pm 0.9$ & 4.9 & 0.20 \\
\hline $3 \mathrm{Pt} 1 \mathrm{Sn} / \mathrm{C}^{\mathrm{f}}$ & 3.0 & 0.6 & 0.19 & $2.9 \pm 0.9$ & 4.7 & 0.21 \\
\hline $3 \mathrm{Pt} 3 \mathrm{Sn} / \mathrm{C}^{\mathrm{f}}$ & 3.0 & 1.8 & 0.16 & $3.7 \pm 1.0$ & 6.1 & 0.16 \\
\hline $3 \mathrm{Pt} 6 \mathrm{Sn} / \mathrm{C}^{\mathrm{f}}$ & 3.0 & 3.7 & 0.11 & $3.1 \pm 0.7$ & 4.2 & 0.24 \\
\hline $3 \mathrm{Pt} / \mathrm{C}-\mathrm{H}^{\mathrm{f}}$ & 3.0 & - & 0.31 & $3.7 \pm 1.1$ & 5.0 & 0.20 \\
\hline $3 \mathrm{Pt} 1 \mathrm{Sn} / \mathrm{C}-\mathrm{H}^{\mathrm{f}}$ & 3.0 & 0.6 & 0.16 & $2.8 \pm 0.8$ & 5.0 & 0.20 \\
\hline $3 \mathrm{Pt} 3 \mathrm{Sn} / \mathrm{C}-\mathrm{H}^{\mathrm{f}}$ & 3.0 & 1.8 & 0.13 & $3.8 \pm 1.0$ & 7.4 & 0.14 \\
\hline $3 \mathrm{Pt} 6 \mathrm{Sn} / \mathrm{C}-\mathrm{H}^{\mathrm{f}}$ & 3.0 & 3.7 & 0 & $3.2 \pm 0.9$ & 5.6 & 0.18 \\
\hline 3Pt3Sn/C-H-R ${ }^{\mathrm{g}}$ & 3.0 & 1.8 & N/A & $3.6 \pm 0.9$ & 6.6 & 0.15 \\
\hline $3 \mathrm{Pt} 6 \mathrm{Sn} / \mathrm{C}-\mathrm{H}-\mathrm{R}^{\mathrm{g}}$ & 3.0 & 3.7 & N/A & $3.1 \pm 0.9$ & 4.9 & 0.20 \\
\hline
\end{tabular}

a: Nominal weight loading.

b: Determined from $\mathrm{H}_{2}$-chemisorption, assuming a nominal loading of Pt.

c: Fitted from TEM using Cauchy-Lorentz distribution.

d: Obtained from TEM by calculating $\Sigma d^{3} / \Sigma d^{2}$.

e: Estimated from the inverse of surface-weight average diameter $(1 / \mathrm{d}){ }^{50}$.

f: Catalysts prior to reaction.

g: Catalysts collected after $4 \mathrm{~h}$ of 1,6-hexanediol oxidation reaction. 
Table 2. XPS binding energies $(\mathrm{Pt}, \mathrm{Sn})$ and surface compositions of $3 \mathrm{Pt} 3 \mathrm{Sn} / \mathrm{C}$, 3Pt3Sn/C-H and 3Pt3Sn/C-H-R

\begin{tabular}{|c|c|c|c|c|c|c|c|c|c|}
\hline \multirow{4}{*}{ Catalysts } & \multicolumn{4}{|c|}{ Binding Energy (eV) } & \multirow{4}{*}{$\begin{array}{l}\operatorname{Pt}(0) \\
(\%)\end{array}$} & \multirow{4}{*}{$\begin{array}{l}\mathrm{Pt}(\mathrm{II}) \\
(\%)\end{array}$} & \multirow{4}{*}{$\begin{array}{l}\operatorname{Sn}(0) \\
(\%)\end{array}$} & \multirow{4}{*}{$\begin{array}{c}\mathrm{Sn}(\mathrm{II}, \mathrm{IV}) \\
(\%)\end{array}$} & \multirow{3}{*}{$\begin{array}{l}\mathrm{Sn} / \mathrm{Pt}^{\mathrm{d}} \\
\text { (atomic }\end{array}$} \\
\hline & $\operatorname{Pt}(0)$ & $\mathrm{Pt}(\mathrm{II})$ & $\operatorname{Sn}(0)$ & $\mathrm{Sn}(\mathrm{II}, \mathrm{IV})^{\mathrm{c}}$ & & & & & \\
\hline & & & & & & & & & \\
\hline & $4 f_{7 / 2}$ & $4 f_{7 / 2}$ & $3 d_{5 / 2}$ & $3 d_{5 / 2}$ & & & & & ratio) \\
\hline $3 \mathrm{Pt} 3 \mathrm{Sn} / \mathrm{C}^{\mathrm{a}}$ & 70.8 & 72.7 & 485.8 & 486.8 & 83 & 17 & 22 & 78 & 1.3 \\
\hline $3 \mathrm{Pt} 3 \mathrm{Sn} / \mathrm{C}-\mathrm{H}^{\mathrm{a}}$ & 71.0 & -- & 485.8 & 486.8 & 100 & 0 & 32 & 68 & 2.1 \\
\hline $3 \mathrm{Pt} 3 \mathrm{Sn} / \mathrm{C}-\mathrm{H}-\mathrm{R}^{\mathrm{b}}$ & 70.5 & -- & 485.8 & 487.1 & 100 & 0 & 13 & 87 & 2.4 \\
\hline
\end{tabular}

a: Catalyst prior to reaction.

b: Catalyst collected after $4 \mathrm{~h}$ of 1,6-hexanediol oxidation.

c: The difference in binding energy of $\mathrm{Sn}(\mathrm{II})$ and $\mathrm{Sn}(\mathrm{IV})$ is only $0.2 \mathrm{eV}$, which could not be reliably differentiated.

d: Corrected by atomic subshell photoionization cross sections of corresponding element ${ }^{47}$. 
Table 3. Elemental compositions from EDS of 3Pt3Sn/C, 3Pt3Sn/C-H and $3 \mathrm{Pt} 3 \mathrm{Sn} / \mathrm{C}-\mathrm{H}-\mathrm{R}^{\mathrm{a}}$

\begin{tabular}{|c|c|c|c|c|c|c|c|}
\hline Sample & Area & $\begin{array}{c}\mathrm{Pt} \\
(\operatorname{mole} \%)\end{array}$ & $\begin{array}{c}\text { Sn } \\
(\text { mole } \%)\end{array}$ & Sample & Area & $\begin{array}{c}\mathrm{Pt} \\
(\mathrm{mole} \%)\end{array}$ & $\begin{array}{c}\mathrm{Sn} \\
(\operatorname{mole} \%)\end{array}$ \\
\hline \multirow{7}{*}{$3 \mathrm{Pt} 3 \mathrm{Sn} / \mathrm{C}$} & a1 & 65 & 35 & \multirow{7}{*}{ 3Pt3Sn/C-H } & b1 & 49 & 51 \\
\hline & a2 & 67 & 33 & & b2 & 45 & 55 \\
\hline & a3 & 91 & 9 & & b3 & 46 & 53 \\
\hline & & & & & & & \\
\hline & a4 & 68 & 32 & & b4 & 56 & 44 \\
\hline & a5 & 31 & 69 & & b5 & 51 & 49 \\
\hline & overall & 54 & 46 & & overall & 48 & 52 \\
\hline \multirow{7}{*}{ 3Pt3Sn/C-H-R } & $\mathrm{c} 1$ & 42 & 58 & \multirow{7}{*}{$3 \mathrm{Pt} 3 \mathrm{Sn} / \mathrm{C}-\mathrm{H}-\mathrm{R}^{\mathrm{c}}$} & $\mathrm{d} 1$ & 97 & 3 \\
\hline & c2 & 52 & 48 & & $\mathrm{~d} 2$ & 81 & 19 \\
\hline & c3 & 53 & 47 & & $\mathrm{~d} 3$ & 5 & 95 \\
\hline & & & & & & & \\
\hline & c4 & 56 & 44 & & $\mathrm{~d} 4$ & 54 & 46 \\
\hline & $\mathrm{c} 5$ & 53 & 47 & & d5 & 23 & 67 \\
\hline & overall & 54 & 46 & & overall & 50 & 50 \\
\hline
\end{tabular}

a: The corresponding regions for EDS analysis are shown in Fig. 6.

b: Catalyst collected after 15 min of 1,6-hexanediol oxidation.

c: Catalyst collected after 4 h of 1,6-hexanediol oxidation. 
Table 4. Initial rate of selective oxidation of 1,6-hexanediol over $\mathrm{PtSn} / \mathrm{C}$ and $\mathrm{PtSn} / \mathrm{C}-\mathrm{H}^{\mathrm{a}}$.

\begin{tabular}{|c|c|c|c|c|c|c|}
\hline \multirow[t]{2}{*}{ Catalyst } & \multirow{2}{*}{$\begin{array}{c}\text { Conversion } \\
\text { (\%) }\end{array}$} & \multicolumn{4}{|c|}{ Selectivity $(\%)^{\mathrm{b}}$} & \multirow[t]{2}{*}{$\operatorname{TOF}\left(\mathrm{s}^{-1}\right)^{\mathrm{c}}$} \\
\hline & & ALD & HA & $\mathrm{AA}$ & DA & \\
\hline $3 \mathrm{Pt} / \mathrm{C}$ & 20 & 89 & 11 & 0 & 0 & 0.44 \\
\hline 3Pt1Sn/C & 21 & 82 & 16 & 2 & 0 & 0.45 \\
\hline 3Pt3Sn/C & 22 & 84 & 14 & 2 & 0 & 0.61 \\
\hline 3Pt6Sn/C & 26 & 80 & 17 & 3 & 0 & 0.50 \\
\hline $3 \mathrm{Pt} / \mathrm{C}-\mathrm{H}$ & 22 & 86 & 13 & 1 & 0 & 0.49 \\
\hline $3 \mathrm{Pt} 1 \mathrm{Sn} / \mathrm{C}-\mathrm{H}$ & 14 & 83 & 17 & 0 & 0 & 0.30 \\
\hline 3Pt3Sn/C-H & 12 & 84 & 16 & 0 & 0 & 0.38 \\
\hline 3Pt6Sn/C-H & 6 & 88 & 12 & 0 & 0 & 0.14 \\
\hline
\end{tabular}

a: Reaction conditions: $10 \mathrm{~cm}^{3} 0.1 \mathrm{M}$ 1,6-hexanediol aqueous solution, $0.0132 \mathrm{~g}$ catalyst (Pt:HDO = 1:500) $1 \mathrm{MPa} \mathrm{O}, 343 \mathrm{~K}$, reaction time is $15 \mathrm{~min}$.

b: Selectivity to ALD (6-hydroxyhexanal), HA (6-hydroxyhexanoic acid), AA (6-oxohexanoic acid) and DA (adipic acid).

c: TOF is normalized by the Pt content in the sample and the fraction of surface atoms revealed by TEM (Table 1$)$. 
Table 5. Catalytic performance of $\mathrm{PtSn} / \mathrm{C}$ and $\mathrm{PtSn} / \mathrm{C}-\mathrm{H}$ at higher conversion of 1,6-hexanediol ${ }^{\mathrm{a}}$

\begin{tabular}{|c|c|c|c|c|c|c|}
\hline \multirow[t]{2}{*}{ Catalyst } & \multirow{2}{*}{$\begin{array}{c}\text { Conversion } \\
\qquad \%)\end{array}$} & \multicolumn{4}{|c|}{ Selectivity $(\%)^{\mathrm{b}}$} & \multirow[t]{2}{*}{ Number of turmovers } \\
\hline & & ALD & HA & $\mathrm{AA}$ & DA & \\
\hline 3Pt/C & 47 & 69 & 24 & 4 & 2 & $0.9 \times 10^{3}$ \\
\hline 3Pt1Sn/C & 56 & 61 & 29 & 7 & 4 & $1.1 \times 10^{3}$ \\
\hline $3 \mathrm{Pt} 3 \mathrm{Sn} / \mathrm{C}$ & 56 & 61 & 29 & 7 & 4 & $1.4 \times 10^{3}$ \\
\hline 3Pt6Sn/C & 59 & 55 & 31 & 9 & 5 & $1.0 \times 10^{3}$ \\
\hline $3 \mathrm{Pt} / \mathrm{C}-\mathrm{H}$ & 58 & 59 & 30 & 8 & 4 & $1.0 \times 10^{3}$ \\
\hline 3Pt1Sn/C-H & 62 & 53 & 32 & 12 & 4 & $1.3 \times 10^{3}$ \\
\hline $3 \mathrm{Pt} 3 \mathrm{Sn} / \mathrm{C}-\mathrm{H}$ & 59 & 55 & 31 & 9 & 5 & $2.0 \times 10^{3}$ \\
\hline 3Pt6Sn/C-H & 66 & 55 & 30 & 9 & 5 & $1.5 \times 10^{3}$ \\
\hline
\end{tabular}

a: Reaction conditions: $10 \mathrm{~cm}^{3} 0.1 \mathrm{M}$ 1,6-hexanediol aqueous solution, $0.0132 \mathrm{~g}$ catalyst $(\mathrm{Pt}: \mathrm{HDO}=1: 500) 1 \mathrm{MPa} \mathrm{O}_{2}, 343 \mathrm{~K}$, reaction time is $4 \mathrm{~h}$.

b: Selectivity to ALD (6-hydroxyhexanal), HA (6-hydroxyhexanoic acid), AA ( 6-oxohexanoic acid) and DA (adipic acid).

c: Number of turnovers is normalized by the Pt content in the sample and the fraction of surface atoms revealed by TEM (Table 1). 
$40 / 49$

Table 6. Elemental analysis of 3Pt3Sn/C-H and 3Pt3Sn/C-H-R ${ }^{\mathrm{a}}$.

\begin{tabular}{cccccc}
\hline Sample & Pt & Sn & Pt & Sn & Pt:Sn \\
& $(\mathrm{wt} \%)$ & $(\mathrm{wt} \%)$ & $(\mathrm{mmol} / \mathrm{g}$ catalyst $)$ & $(\mathrm{mmol} / \mathrm{g}$ catalyst $)$ & (molar ratio) \\
\hline 3Pt3Sn/C-H & 3.3 & 1.7 & 0.17 & 0.14 & 1.2 \\
$3 \mathrm{Pt} 3 \mathrm{Sn} / \mathrm{C}-\mathrm{H}-\mathrm{R}^{\mathrm{b}}$ & 2.7 & 1.4 & 0.14 & 0.12 & 1.2 \\
\hline
\end{tabular}

a: Analyzed by ICP-AES method.

b: Catalyst was collected after $4 \mathrm{~h}$ of 1,6-hexanediol oxidation 
a)

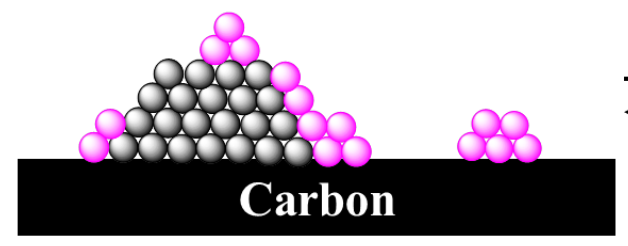

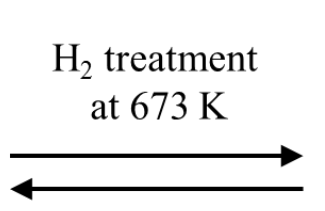

Alcohol oxidation

in water b)

b)

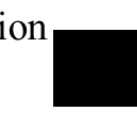

$\mathrm{Pt}$

Sn or

$\mathrm{SnO}_{\mathrm{x}}$

Scheme 1. Illustration of restructuring between a) separate $\mathrm{Pt}$ and $\mathrm{SnO}_{\mathrm{x}}$ domains (PtSn/C and PtSn/C-H-R catalysts) and b) Pt-Sn alloy (PtSn/C-H catalysts). Pt and Sn species are grey and pink, respectively (see online article for color). 

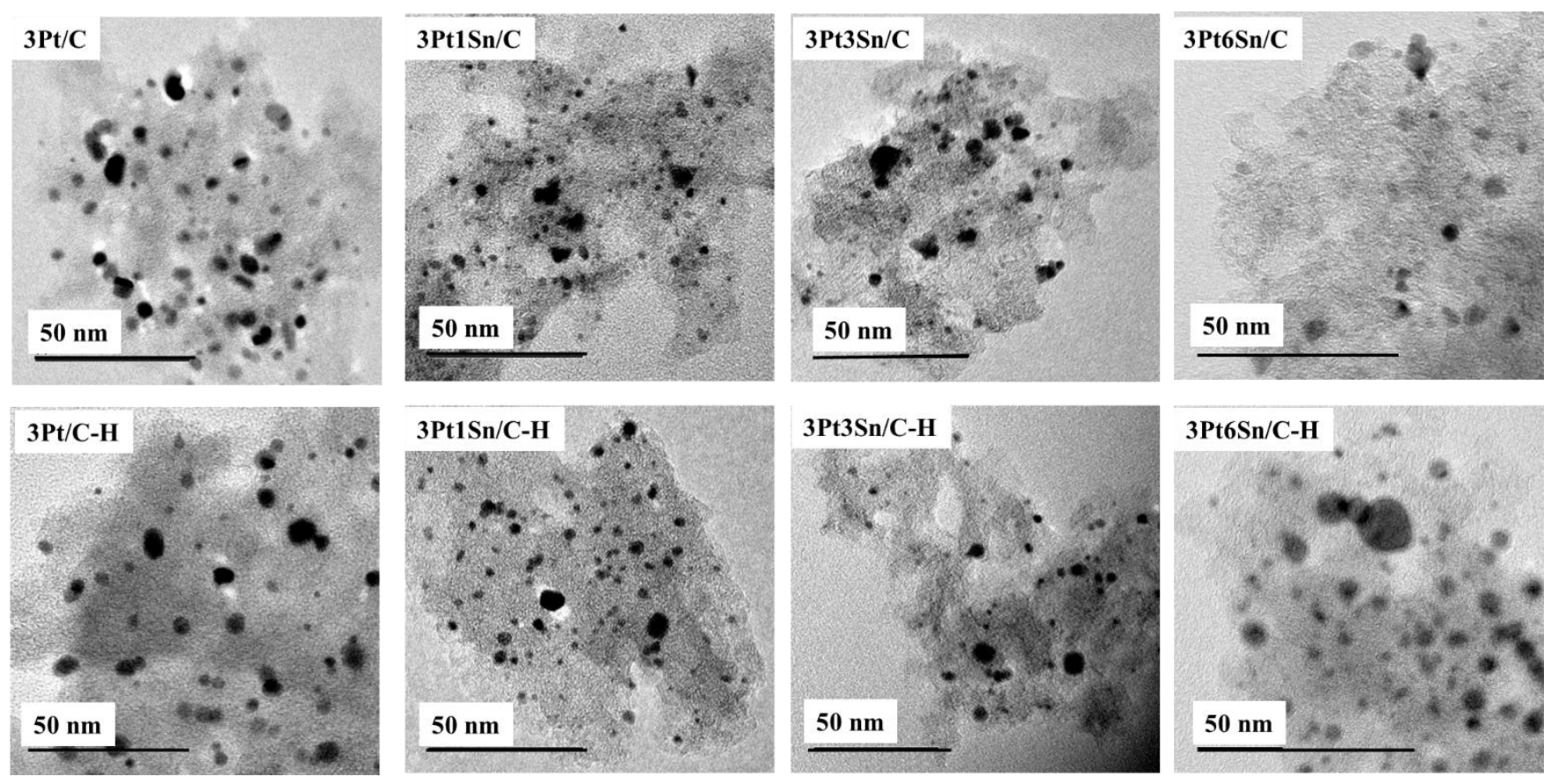

Figure 1. Bright field TEM images of PtSn/C and PtSn/C-H.
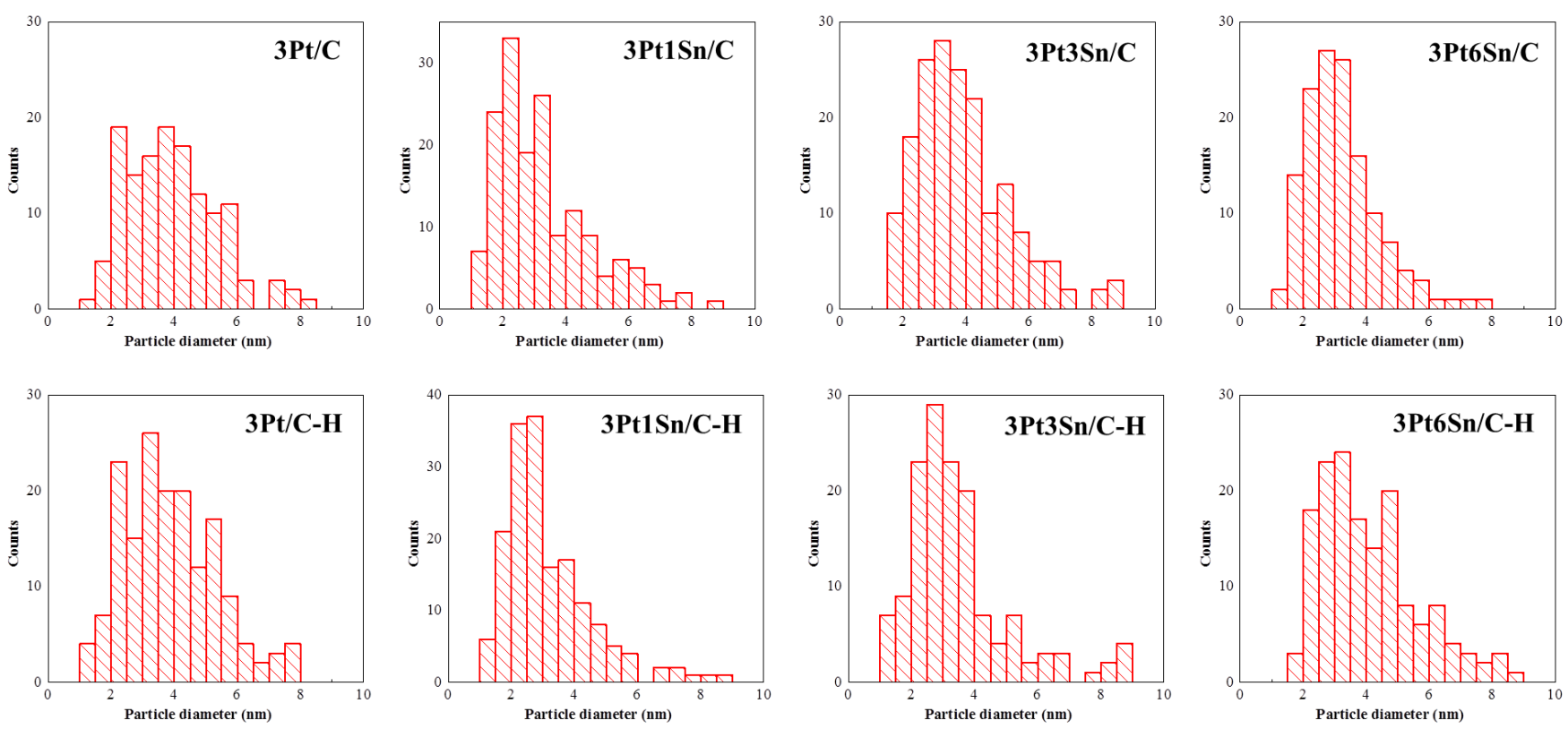

Figure 2. Particle size distributions obtained from TEM of PtSn/C and PtSn/C-H. 

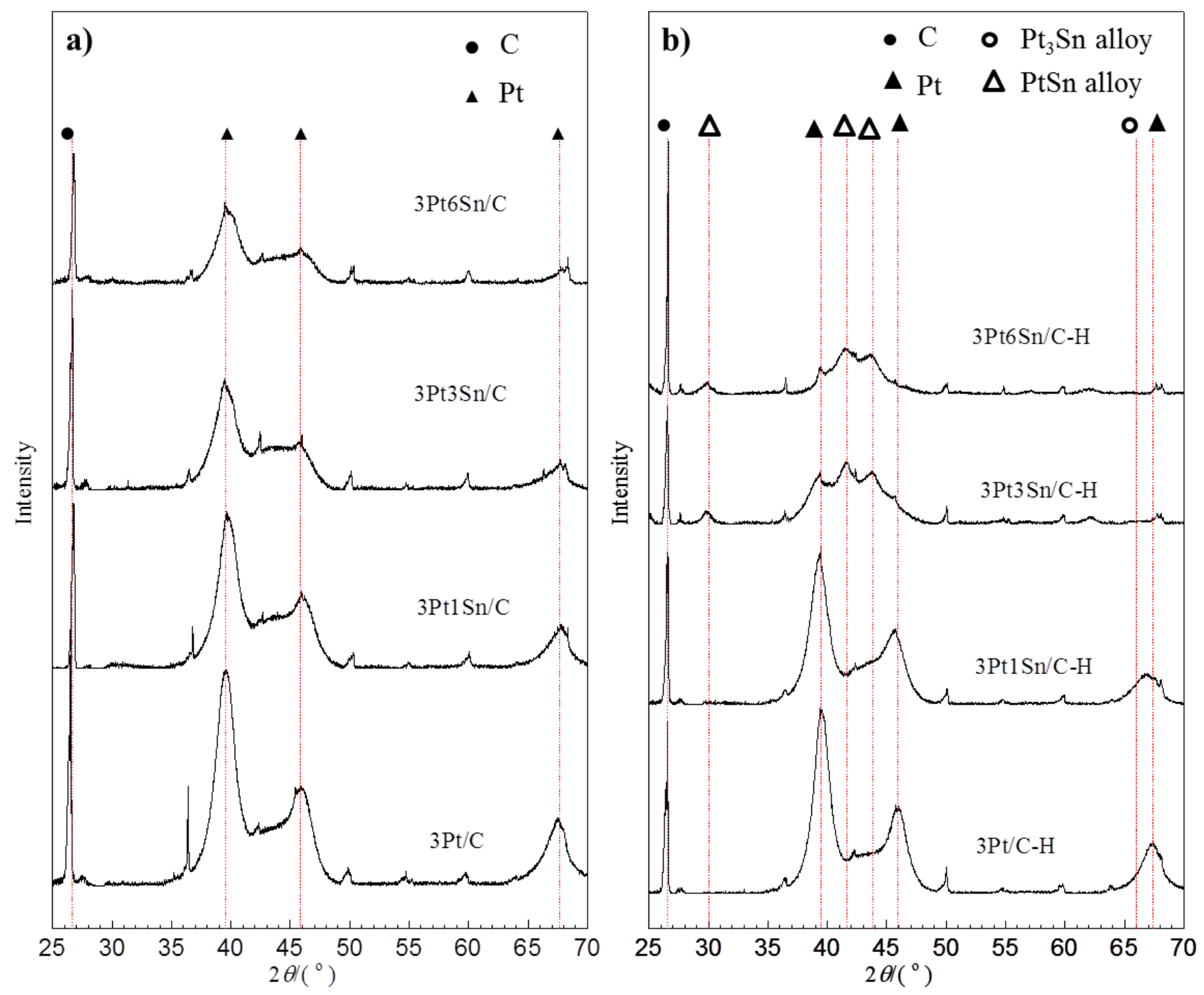

Figure 3. XRD patterns of a) $\mathrm{PtSn} / \mathrm{C}$ and b) $\mathrm{PtSn} / \mathrm{C}-\mathrm{H}$. 

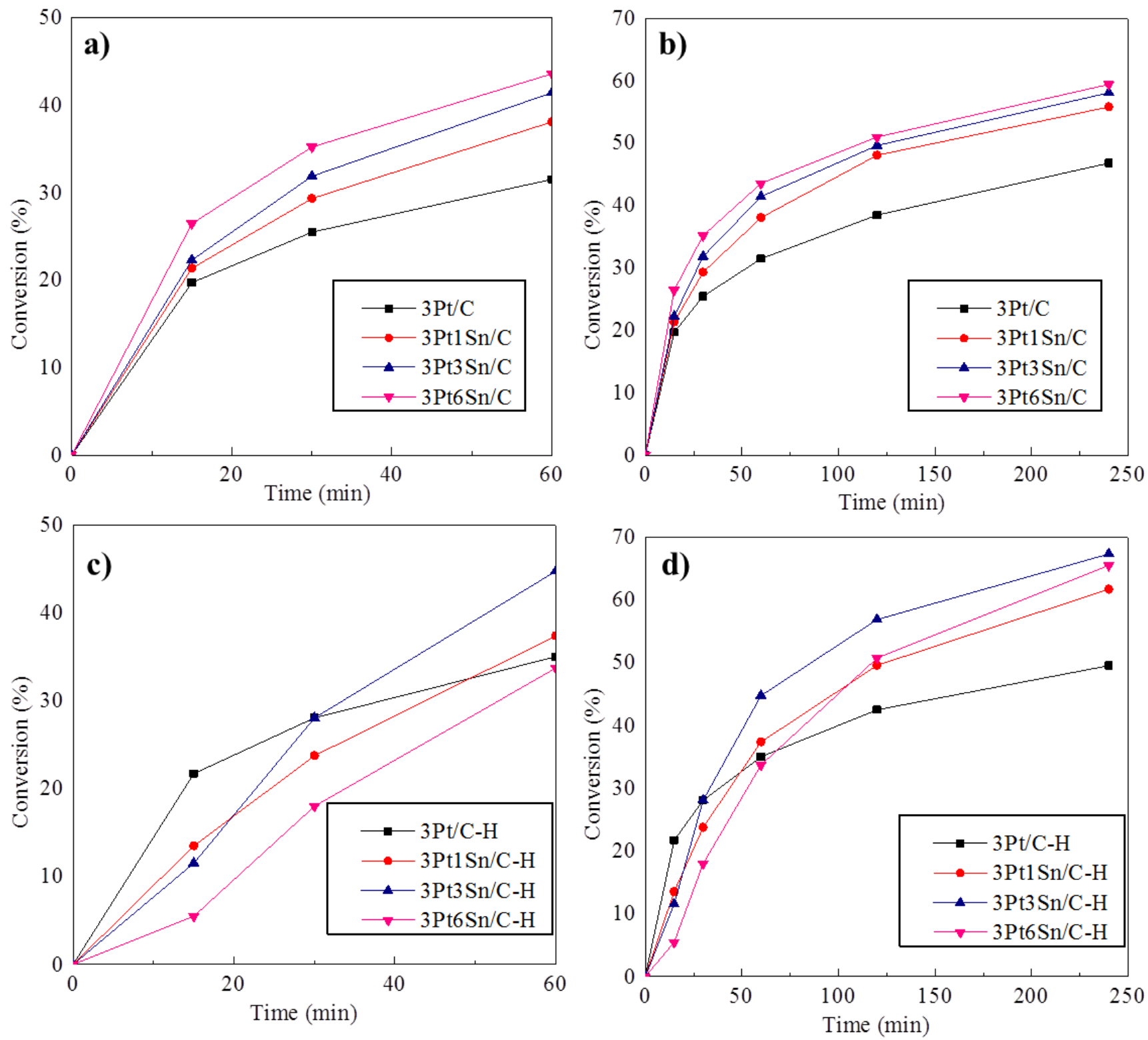

Figure 4. Reaction profiles for 1,6-hexanediol oxidation with $1 \mathrm{MPa}$ oxygen at $343 \mathrm{~K}$ over carbon supported bimetallic PtSn catalysts in the range of a) $0-60$ min and b) $0-$ $4 \mathrm{~h}$ and over Pt-Sn/C CINH in the range of c) $0-60 \mathrm{~min}$ and d) $0-4 \mathrm{~h}$. 

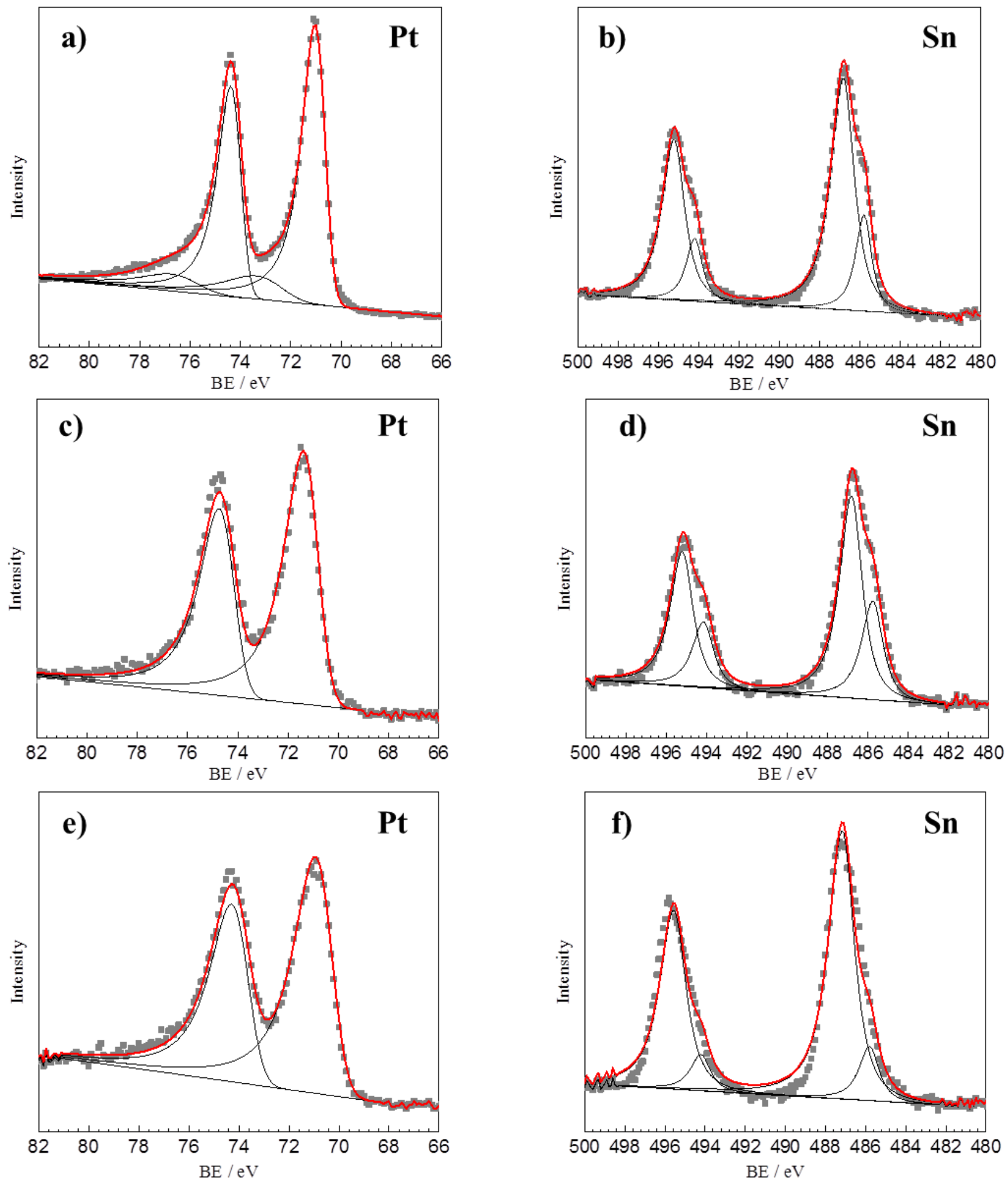

Figure 5. The $\mathrm{Pt} 4 \mathrm{f}_{7 / 2} \mathrm{X}$-ray photoemission spectra of a) $3 \mathrm{Pt} 3 \mathrm{Sn} / \mathrm{C}$, c) $3 \mathrm{Pt} 3 \mathrm{Sn} / \mathrm{C}-\mathrm{H}$ and e) 3Pt3Sn/C-H-R (collected after $4 \mathrm{~h}$ of HDO oxidation) and the $\mathrm{Sn} 3 \mathrm{~d}_{5 / 2}$ spectra of b) $3 \mathrm{Pt} 3 \mathrm{Sn} / \mathrm{C}$, d) $3 \mathrm{Pt} 3 \mathrm{Sn} / \mathrm{C}-\mathrm{H}$ and f) $3 \mathrm{Pt} 3 \mathrm{Sn} / \mathrm{C}-\mathrm{H}-\mathrm{R}$ (collected after $4 \mathrm{~h}$ of 1,6-hexanediol oxidation). The grey dots are the actual data points and the red solid lines are the results from peak fitting. 

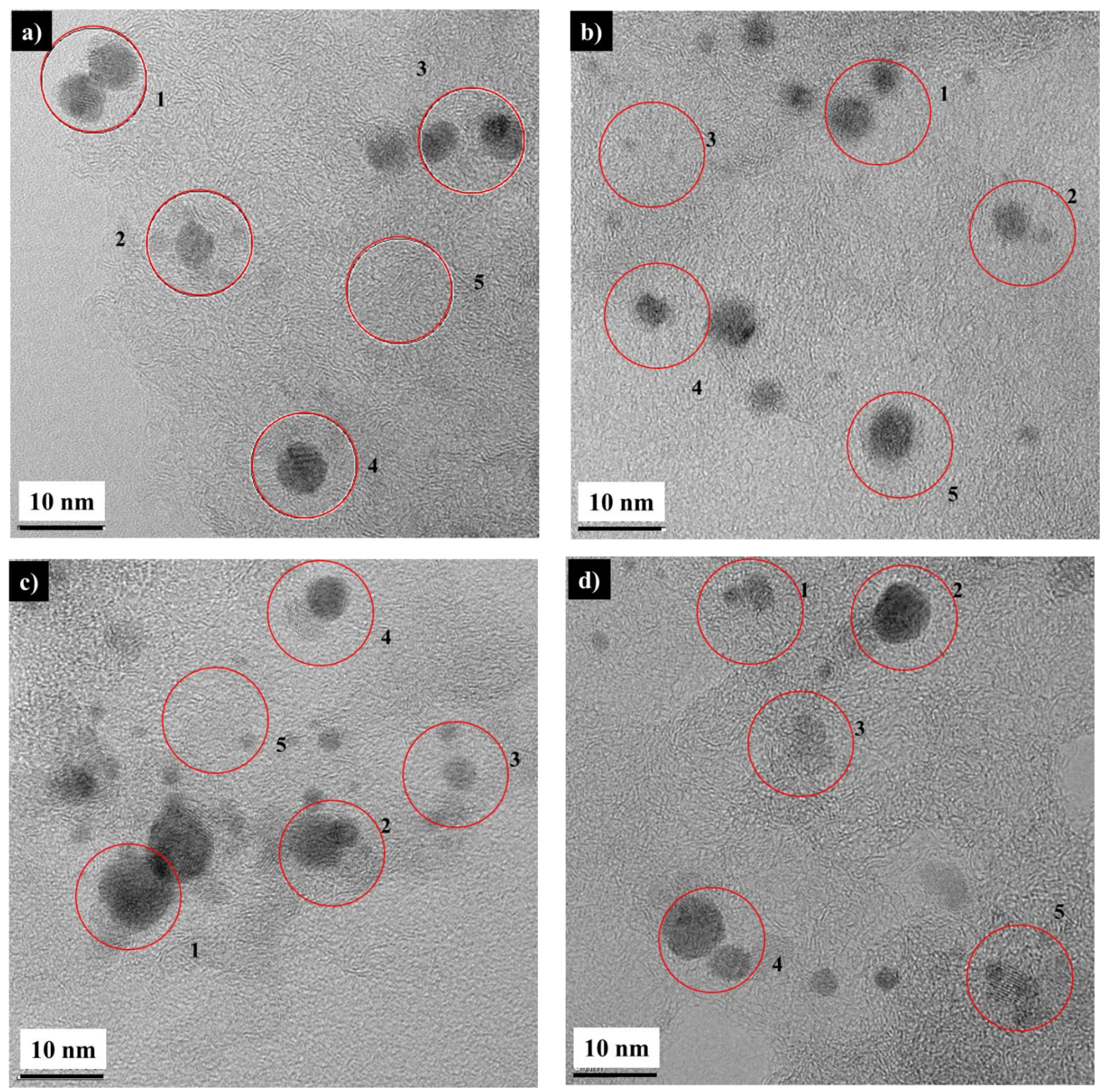

Figure 6. Regions for EDS analysis of a) $3 \mathrm{Pt} 3 \mathrm{Sn} / \mathrm{C}$ and b) $3 \mathrm{Pt} 3 \mathrm{Sn} / \mathrm{C}-\mathrm{H}$ and

3Pt3Sn/C-H-R catalysts collected after c) $15 \mathrm{~min}$ and d) $4 \mathrm{~h}$ of 1,6-hexanediol

oxidation. The corresponding compositions are shown in Table 3. 

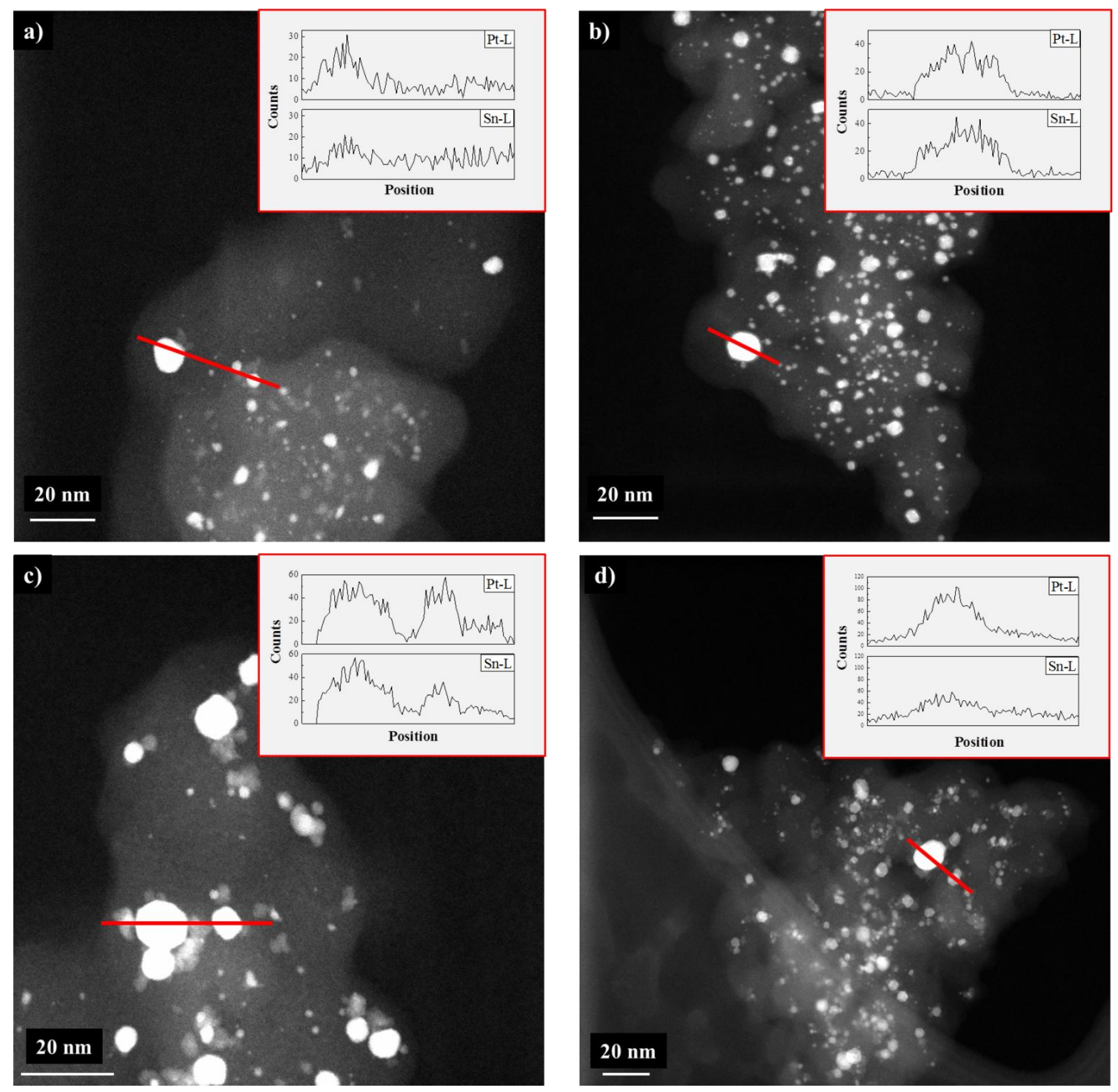

Figure 7. STEM-EDS line scans of a) $3 \mathrm{Pt} 3 \mathrm{Sn} / \mathrm{C}$ and b) $3 \mathrm{Pt} 3 \mathrm{Sn} / \mathrm{C}-\mathrm{H}$ and $3 \mathrm{Pt} 3 \mathrm{Sn} / \mathrm{C}-\mathrm{H}-\mathrm{R}$

collected after c) 15 min and d) $4 \mathrm{~h}$ of 1,6-hexanediol oxidation. 

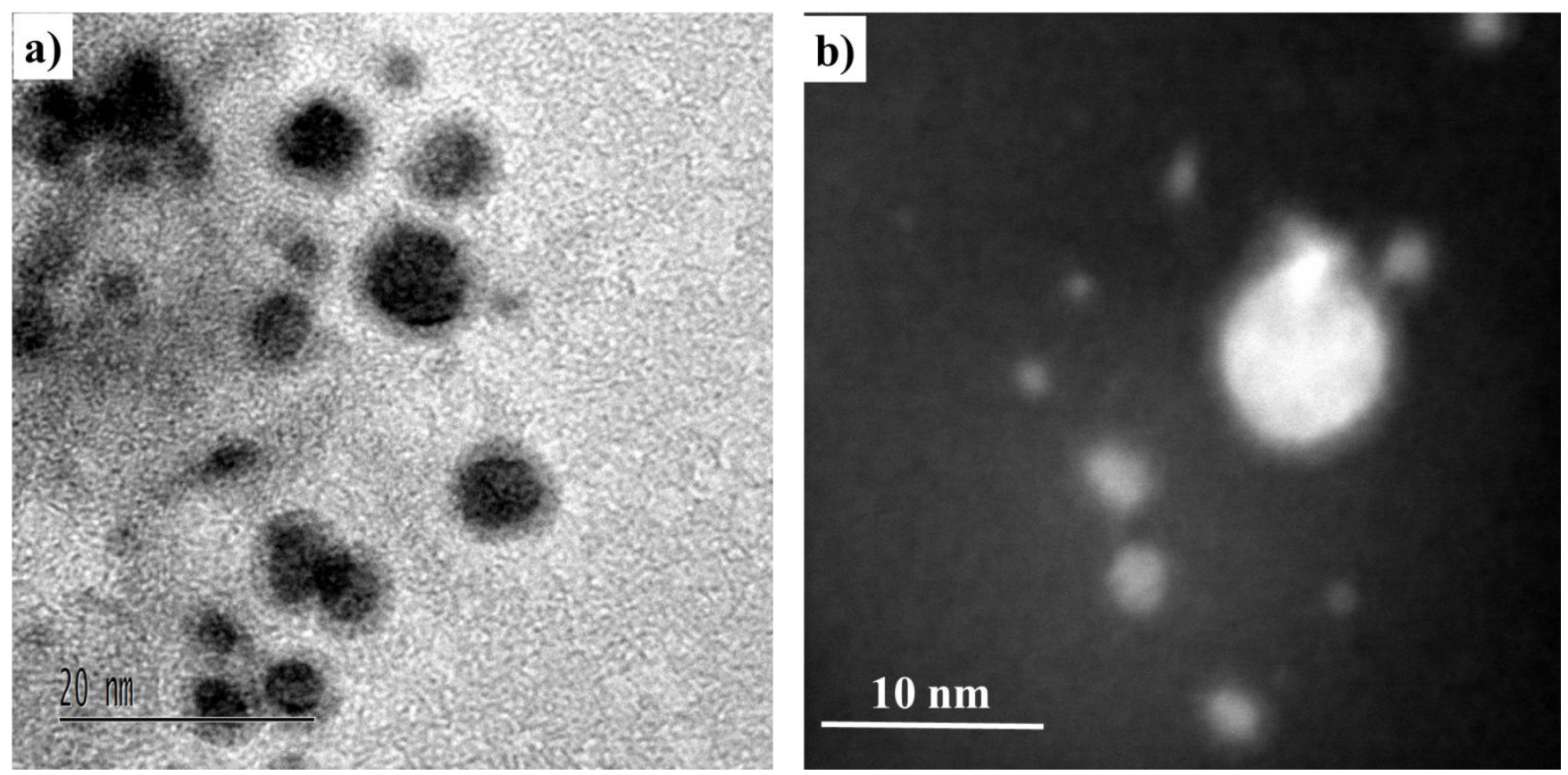

Figure 8. a) Bright field TEM and b) dark field STEM image of 3Pt6Sn/C-H. 


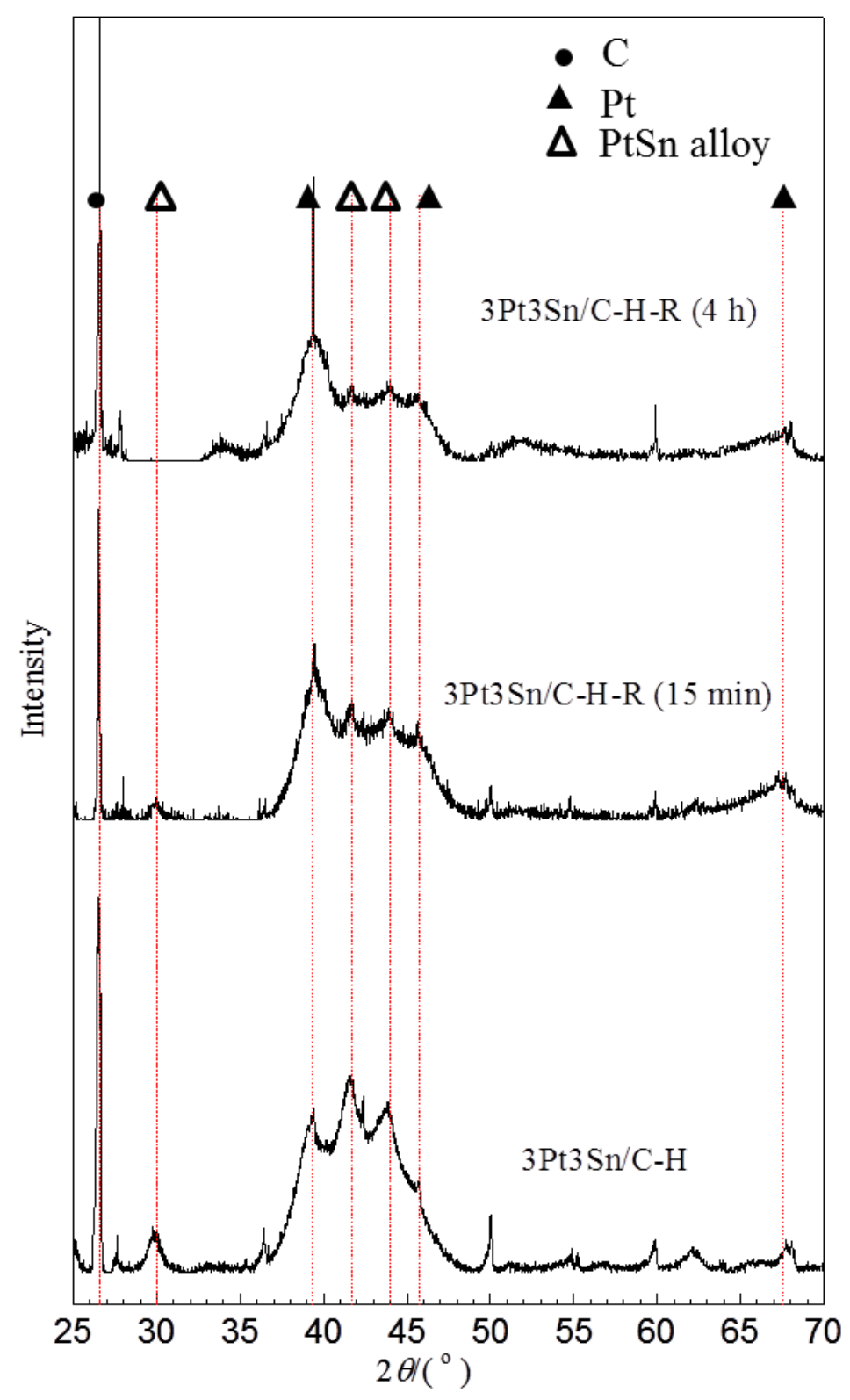

Figure 9. XRD patterns of 3Pt3Sn/C-H and 3Pt3Sn/C-H-R collected after 15 min and 4 h of 1,6-hexanediol oxidation. 


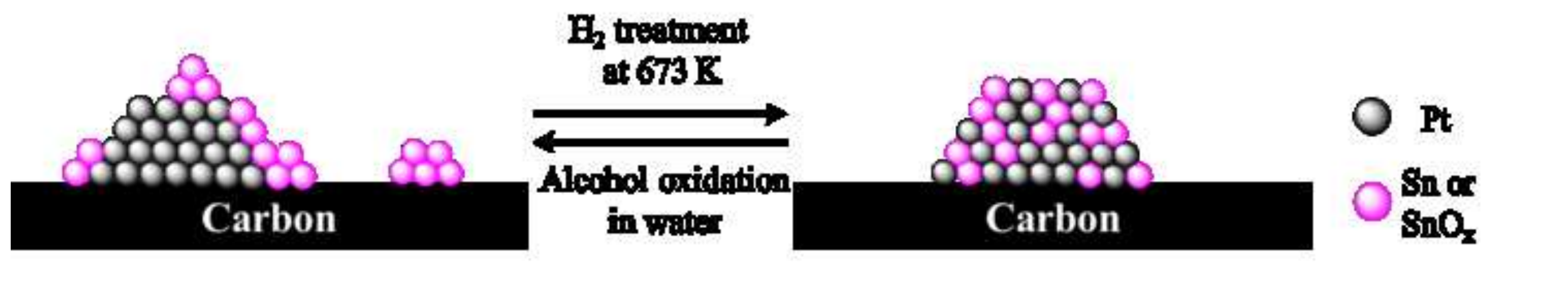

.

.

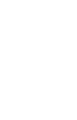

.
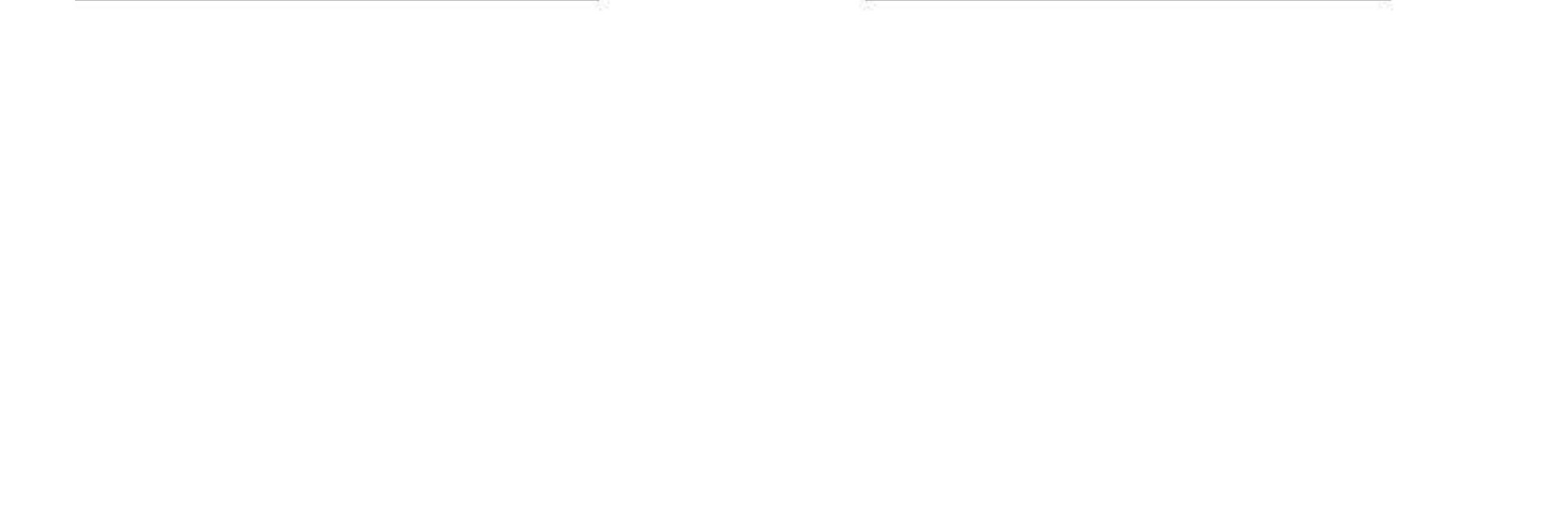